\title{
MicroRNAs, Hypoxia and the Stem-Like State as Contributors to Cancer Aggressiveness
}

\author{
Lucy Wanjiku Macharia 1,2, Caroline Muriithi Wanjiru1,3, Marianne Wanjiru Mureithi4, \\ Claudia Maria Pereira ${ }^{5}$, Valéria Pereira Ferrer ${ }^{1,2+}$ and Vivaldo Moura-Neto ${ }^{1,2 * t}$ \\ ${ }^{1}$ Instituto Estadual do Cérebro Paulo Niemeyer - Secretaria de Estado de Saúde, Rio de Janeiro, Brazil, ${ }^{2}$ Programa \\ de Pós-Graduação em Anatomia Patológica, Faculdade de Medicina da Universidade Federal do Rio de Janeiro, Rio \\ de Janeiro, Brazil, ${ }^{3}$ Instituto de Ciências Biomédicas da Universidade Federal do Rio de Janeiro, Rio de Janeiro, Brazil, \\ ${ }^{4}$ KAVI Institute of Clinical Research, Faculty of Medicine, University of Nairobi, Nairobi, Kenya, ${ }^{5}$ Laboratório de Genética, \\ Universidade do Grande Rio, Duque de Caxias, Brazil
}

OPEN ACCESS

Edited by:

Ondrej Slaby,

Central European Institute of Technology (CEITEC), Czechia

Reviewed by:

Rajneesh Pathania,

National Institute of Environmental Health Sciences (NIEHS),

United States

Neha Nagpal,

Boston Children's Hospital,

United States

*Correspondence:

Vivaldo Moura-Neto vivaldomouraneto@gmail.com

${ }^{\dagger}$ These authors have contributed equally to this work

Specialty section: This article was submitted to RNA,

a section of the journal

Frontiers in Genetics

Received: 19 September 2018 Accepted: 04 February 2019

Published: 20 February 2019

Citation:

Macharia LW, Wanjiru CM,

Mureithi MW, Pereira CM, Ferrer VP and Moura-Neto V (2019)

MicroRNAs, Hypoxia and the Stem-Like State as

Contributors to Cancer Aggressiveness.

Front. Genet. 10:125

doi: 10.3389/fgene.2019.00125
MicroRNAs (miRNAs) are small non-coding RNA molecules that play key regulatory roles in cancer acting as both oncogenes and tumor suppressors. Due to their potential roles in improving cancer prognostic, predictive, diagnostic and therapeutic approaches, they have become an area of intense research focus in recent years. Several studies have demonstrated an altered expression of several miRNAs under hypoxic condition and even shown that the hypoxic microenvironment drives the selection of a more aggressive cancer cell population through cellular adaptations referred as the cancer stem-like cell. These minor fractions of cells are characterized by their self-renewal abilities and their ability to maintain the tumor mass, suggesting their crucial roles in cancer development. This review aims to highlight the interconnected role between miRNAs, hypoxia and the stem-like state in contributing to the cancer aggressiveness as opposed to their independent contributions, and it is based in four aggressive tumors, namely glioblastoma, cervical, prostate, and breast cancers.

Keywords: microRNAs, hypoxia, stem-like state, cancer, cancer aggressiveness, microenvironment

Abbreviations: 5-mC, 5-methylcytosine; ACC, cervical adenocarcinoma; ADT, androgen deprivation therapy; AGO, argonaute; AMOs, antisense miRNA oligonucleotides; AR, androgen receptor; ATM, ataxia-telangiectasia; $\mathrm{BP}$, base pairs; BRCA1, Breast cancer 1; CA125, Carbohydrate antigen 125; CC, cervical cancer; CHEK2, checkpoint kinase 2; CIN, cervical intraepithelial neoplasia; CSC, Cancer stem-like cells; DGCR8, DiGeorge syndrome critical region 8; DHT, dihydrotestosterone; DNA, deoxyribonucleic acid; DNMTs, DNA methyltransferases; dsRBPs, dsRNA-binding proteins; EGFR, epithelial growth factor receptor; ELF, eukaryotic initiation factors; EMT, epithelial to mesenchymal transition; ER, estrogen receptor; Exp5, exportin 5; FFPE, Formalin fixed paraffin -embedded; GB, glioblastoma; GST, Glutathione S-transferase; GW182, glycine tryptophan protein of $182 \mathrm{kDa}$; H3K27me3, trimethylated histone H3 lysine 27; HATs, histone acetyltransferases; HDACs, histone deacetylases; HER2, human epidermal growth factor receptor type 2; HIF, hypoxia indicible factor; HNPRK, heterogeneous nuclear ribonucleoprotein K; HRE, HIF responsive element; HRMs, hypoxiaregulated miRNAs; IDH, isocitrate dehydrognase; IFNG, interferon, gamma; IGF, insulin growth factor; IPSC, induced pluripotent stem cells; KGF, Keratinocyte growth factor; lnRNA, long non-coding RNA; MEF, mouse embryonic fibroblast; MGMT, O(6)-methylguanine-DNA methyltransferase; miRISC, miRNA-induced silencing complex; miRNAs, MicroRNAs; NTS, Nucleotides; OCT4, Octamer-binding transcription factor 4; ODDD, oxygen-dependent degradation domain; PABP, poly A-binding protein; PAZ, Piwi, Argonaute and Zwille; PCa, prostate cancer; PHD, prolyl hydroxylases; piRNA, Piwi RNA; PR, progesterone receptors; pre-miRNA, precursor miRNA; pri-miRNA, primary miRNA; PSA, prostate specific antigen; PSCA, prostate stem cell antigen; PTEN, phosphatase and tensin homolog; SCC, squamous cell carcinoma; SDF-1, Stromal derived factor 1; siRNA, Small interfering RNA; SOX2, SRY-like HMG-box gene; TARBP, Transactivation responsive RNA binding protein; TERT, telomerase reverse transcriptase; TMC6/8, transmembrane channel-like 6 and 8; TNBC, tripple negative breast cancer; TP53, tumor Protein 53; UTR, untranslated region; VEGF, vascular endothelial growth factor; VHL, von Hippel -Lindau; VMP1, Vacuole membrane protein 1; ZEBI, Zinc finger E-box binding homeobox 1. 


\section{INTRODUCTION}

About $70-80 \%$ of the human genome is transcribed into RNA and only about $2 \%$ of the human genome constitutes protein-coding genes meaning that the rest of the genome contains more non-coding genes mostly referred to as noncoding RNA (ncRNA). Additionally, ncRNAs include long noncoding RNAs (lncRNA), PIWI-interacting RNAs (piRNA), small interfering RNAs (siRNA) and microRNAs (miRNA) among others (Alexander et al., 2010; Sana et al., 2012; Qureshi and Mehler, 2012; Kartha and Subramanian, 2014). However, approximately $60 \%$ of all protein-coding genes are potentially regulated by miRNAs, which confers them a fundamental role in the modulation of numerous cell processes and disorders, such as cancer (Bartel, 2009; Ma et al., 2012). Several miRNAs play important roles during hypoxia, an essential feature of the neoplastic microenvironment (Harris, 2002; Vaupel et al., 2004) and the molecular mechanisms responsible for the hypoxic survival of neoplastic cells are not fully characterized. A better understanding of this process may lead to novel strategies for pharmacological intervention. Moreover, hypoxia has been associated with maintenance of an undifferentiated cell state (Parmar et al., 2007; Clarke and van der Kooy, 2009; Silván et al., 2009) and several studies have shown that restricted oxygen conditions expand the fraction of cells positive for a cancer stem cell marker (Tavaluc et al., 2007; Das et al., 2008; McCord et al., 2009). Hypoxia and the stem-like state influence the expression profile of a set of miRNAs and the same miRNAs play prosurvival roles in this microenvironment and in the maintenance of the tumor cell in its precursor state. Various studies show that miRNAs, the stem-like state and the tumor microenvironment all play important roles in the tumor invasiveness, but their interconnected roles will be further explored in this article.

\section{MicroRNAs}

MicroRNAs are small non-coding RNAs composed of approximately 21-22 nucleotides (nts) and were first discovered in Caenorhabditis elegans (Lee et al., 1993). Their biogenesis generally starts from transcription of intergenic, intronic or polycistronic loci by RNA polymerase II (Lee et al., 2004; Borchert et al., 2006) to a 80-nts, capped, polyadenylated primiRNA transcripts bearing a stem-loop structure (Figure 1). In the canonical pathway, nuclear RNase III- Drosha, in complex with dsRBPs, for example DGCR8 and transactivationresponsive (TAR) RNA-binding protein (TRBP) in mammals, cleaves the pri-miRNA to give rise to a 70-nts long RNA molecule with a 2 -nt overhang at the $3^{\prime}$ end called pre-miRNA. Besides the canonical miRNA biogenesis pathway, many DroshaDGCR8- independent pathways produce pre-miRNAs. The most common alternative pathway involves short intronic hairpins termed mirtrons, that are spliced by spliceosome to form looped intermediates, lariat, which then refold into the pre-miRNA hairpins (Ruby et al., 2007; Yang and Lai, 2011; Ladewig et al., 2012; Palanichamy and Rao, 2014). After, the pre-miRNA is exported to the cytoplasm by Exp5, a Ran-GTP dependent nucleo/cytoplasmic cargo transporter (Yi, 2003). Its $3^{\prime}$ overhang is then recognized by Dicer another RNase III enzymes, in complex with transactivation- responsive RNA-binding protein 2 (TARBP2) and binds it to its PAZ domain to cleave the terminal loop, resulting in a 21- to 22-nt double-stranded RNA that contain a 2-nt overhang on both ends termed as mature miRNA (Bernstein et al., 2001; Grishok et al., 2001; Lee et al., 2003; Yi et al., 2003; Bohnsack et al., 2004; Denli et al., 2004). In the cytoplasm, miRNA duplexes are incorporated into an Argonaute (Ago) protein containing miRISC followed by unwinding of the duplex (miRNA/miRNA* duplex) and retention of the mature miRNA strand (guide strand) in miRISC, while the complementary strand (passenger or miRNA*) is released and degraded (Carthew and Sontheimer, 2009; Krol et al., 2010) (Figure 1).

Different levels of complementarity between the miRNA and mRNA can lead to various effects on gene expression. That is, if the complementarity is perfect, miRNA function as short interfering RNA (siRNA) and the target mRNA is sequencespecifically cleaved by the miRISC complex. However, this occurrence is rare in animals and imperfect complementarity happens where the miRNA seed region, nucleotides 2-8 in the mature miRNA, base pairs (BPs) perfectly with the complementary seed match site in the $3^{\prime}$ untranslated region (3' UTR) of the target mRNA (Bartel, 2009) consequently leading to translational repression or mRNA degradation (Krol et al., 2010; Huntzinger and Izaurralde, 2011). Further, glycinetryptophan protein of $182 \mathrm{kDa}$ (GW182), a core component of miRISC, mediates deadenylation of mRNAs by interacting with AGO and poly (A) binding protein (PABP) consequently leading to recruitment of deadenylases like CCR4 and CAF1 (Eulalio et al., 2009; Fabian et al., 2010). The formation of the CCR4-CAF1-NOT complex, a poly A tail-truncating enzyme, mediated by binding of miRISC to mRNA, results in truncation of the downstream poly A tail, reduced binding of translation initiation factors and translation repression (Wu et al., 2006; Standart and Jackson, 2007; Torres et al., 2011). The shortening or complete removal of the poly (A) tail induces the removal of the $5^{\prime}$ cap of the mRNA. Consequently, the uncapped mRNA is rapidly degraded by $5^{\prime}-3^{\prime}$ exoribonucleases (Treiber et al., 2012) (Figure 1).

\section{miRNAs and Cancer Aggressiveness}

In this article, tumor aggressiveness is a term used to refer to a highly invasive, incurable, end stage cancer associated with therapy resistance and a poor patient prognosis (Lima et al., 2012; Arpino et al., 2015; Small et al., 2017).

miRNAs are dysregulated in almost all human cancers (Di Leva et al., 2014; Palanichamy and Rao, 2014) and can function as either oncogenes (oncomirs) or tumor suppressors (antioncomirs), depending on their target transcripts (Figure 2). In the canonical model, oncomirs are upregulated and antioncomirs are downregulated, which has been attributed to amplification, deletion and/or mutation of miRNA loci, dysregulation of transcription factors and epigenetic silencing (Calin et al., 2004; Zhang et al., 2006). Globally, miRNA expression alterations lead to the regulation of several oncogenic 


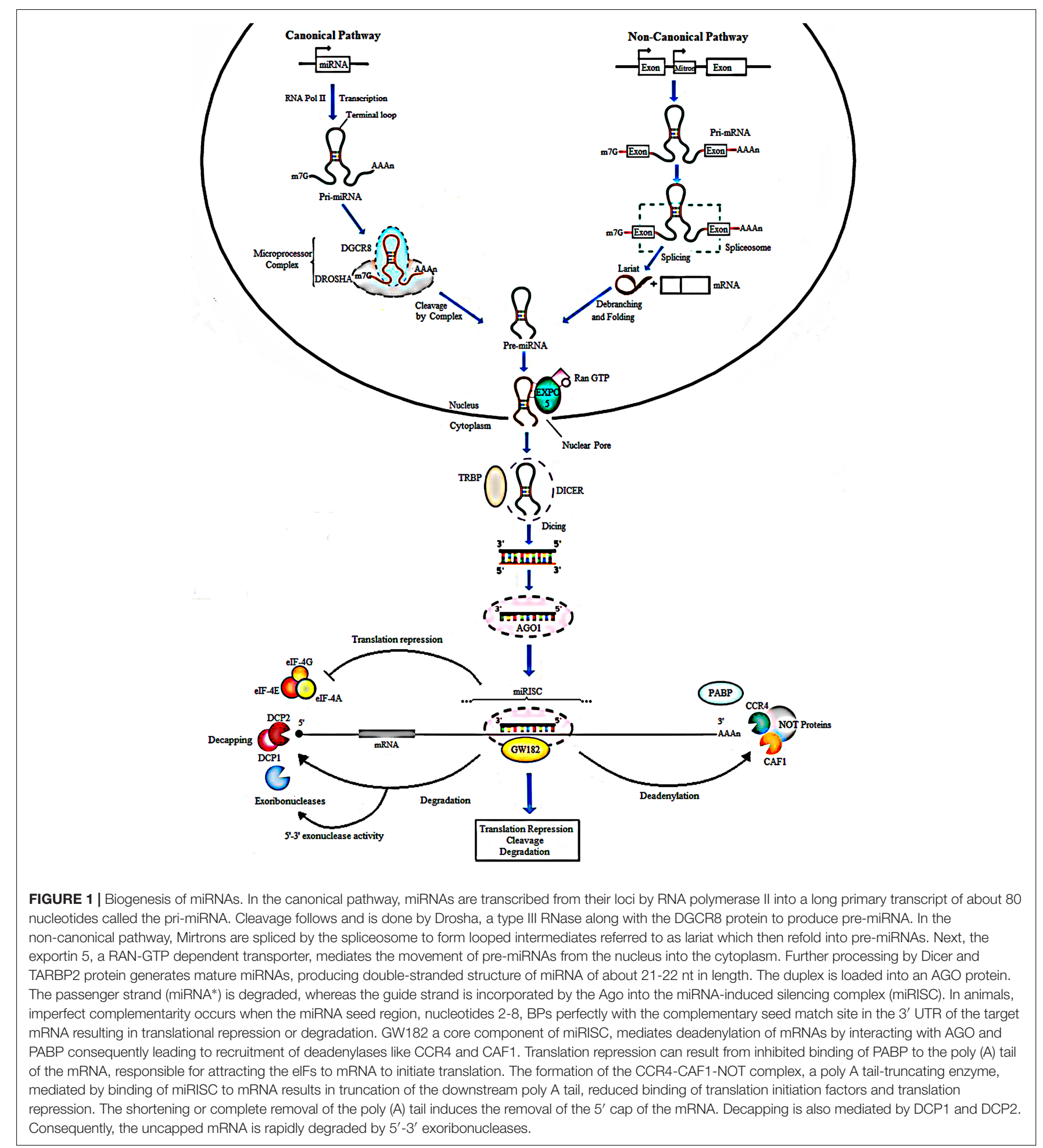

or tumor-suppressor protein levels, which in turn alter cell behavior favoring tumor aggressiveness (Zhang et al., 2007; Iorio and Croce, 2012).

Various studies on individual miRNA function or expression in glioblastoma (GB), cervical (CC), prostate (PCa) and breast cancers (BC), have established that miRNAs play a crucial role in different aspects of tumorigenesis. Specifically, miRNAs mediated mechanisms regulate a wide range of functions including cell viability, cell proliferation (Cui et al., 2010), cell migration and invasion (Zhang et al., 2010; Bao et al., 2018), apoptosis (Shi et al., 2011), tumor growth (Zhu et al., 2018), cell cycle (Peng et al., 2018), chemo- and radio resistance (Ke et al., 


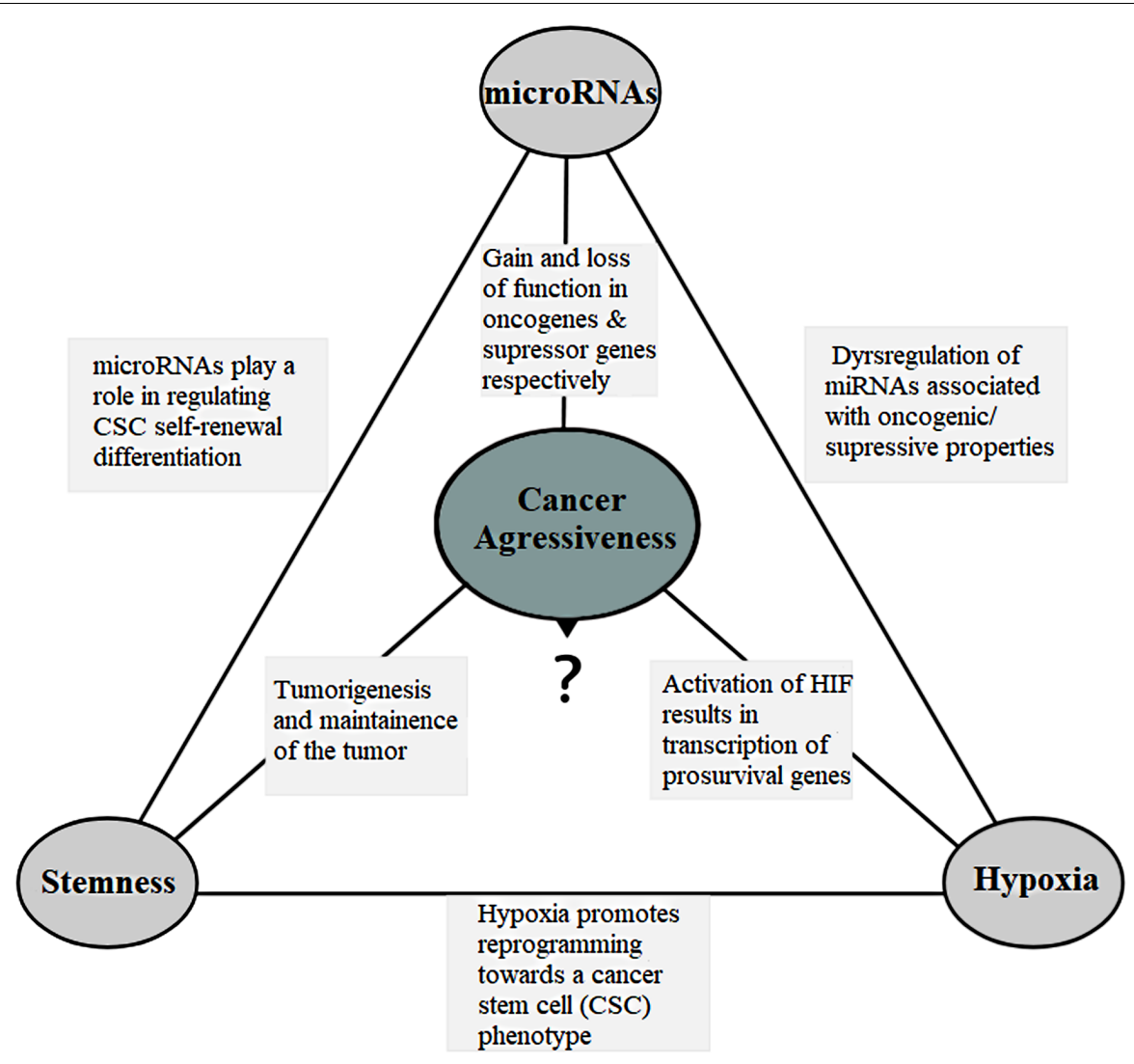

FIGURE 2 | The connection triangle. The miRNAs, hypoxia and the stem-like state all play a connected role that eventually culminates in the tumor aggressiveness. miRNAs and aggressiveness: miRNAs are often found dysregulated and have gain-of-function mutations in the miRNAs associated with the oncogenic property and loss-of-function mutations in the miRNAs with the tumor suppressor properties. miRNAs and stemness: miRNAs play a role in the regulation of cell self-renewal, differentiation and regulation of transcription factors including Nanog, SOX2 and OCT4 among others associated with the stem-like state. They also help the stem-like cells to override the G1/S checkpoint to sustain continual division. miRNAs and hypoxia: miRNAs assist forming hypoxic microenvironment and regulate the HIF switch during hypoxia. Switch of HIF-1 to HIF-2 and HIF-3 is required in order to adapt the cells to prolonged or chronic hypoxia that may otherwise lead to apoptosis. Hypoxia and aggressiveness: In intratumoral hypoxia, a phenomenon of the aggressive cancers, hypoxia inducible factor $1 \alpha(\mathrm{HIF-1} \alpha)$ is stabilized, and in turn, HIF-1 results in transcription of pro-survival target genes involved with tumor angiogenesis, invasion, cell survival, EMT, and metabolism among others. Hypoxic pseudopalisading zones are protected from chemoradiation because of vascular stasis and depletion of molecular oxygen cells contributing to aggressiveness. Hypoxia and miRNAs: under hypoxia, a group of miRNAs, hypoxia regulated miRNAs-HRMs, are deregulated modulating processes involved in tumor survival. Hypoxia and stemness: Hypoxia promotes reprogramming towards a cancer stem-like cell (CSC) phenotype and expansion of CSC populations, a population thought to be responsible for the maintenance and recurrence of the tumor. It is in the hypoxic regions also that the CSCs go into quiescence to escape from targeted therapy. Stemness and aggressiveness: It is believed that stem-like cells have the capacity to sustain tumorigenesis by maintaining the tumor growth. They also contribute to therapy resistance, invasion and metastasis. Stemness and miRNAs: Evidences have shown that stem-like cells fine tune the miRNA expression. This includes "inhibitory-like" role of the miRNAs associated with tumor differentiation to restore "stemness" a probable source for tumor recurrence.

2013; Wang W. et al., 2016), angiogenesis (Yue et al., 2012), tumor metabolism (Liu Z. et al., 2017), epithelial-mesenchymal transformation (Peng et al., 2011), and maintenance of the stemlike state (Shi et al., 2010, 2014; Yang et al., 2015; Wang et al., 2017) among others that culminates to cancer aggressiveness. There are clinical studies focused on assessing miRNA expression patterns to determine its value as a therapeutic, prognostic and diagnostic marker using patient samples. Example of such clinical trials is a study correlating miR-10b with gliomas (ClinicalTrials.gov identifier: NCT01849952). Elsewhere, a study that aimed to evaluate the expression levels of miR-10b in breast cancer patients, showed miR-10b expression to be correlated with disease stage, living status and the tumor size (Zhang et al., 2018). Various other studies linking miRNA and patient prognosis or the clinical response in various diseases are summarized by NanaSinkam and Croce (2013) and Monroig-Bosque et al. (2015).

\section{miRNAs, Epigenetic Mechanisms and Cancer Aggressiveness}

In as much as miRNAs are dysregulated in a variety of cancers, the mechanisms behind their dysregulation are unclear. Research advances have lead to the knowledge that epigenetic alterations, including aberrant DNA methylation and histone modifications, are major causes of miRNA dysregulation in cancer (Suzuki et al., 2013). DNA methylation is mediated by the activation of the enzyme DNA methyltransferase (DNMT) and specifically (DNMT1, DNMT3A, and DNMT3B) have the 
catalytic methyltransferase activity of which DNMT1 is the most abundant DNMT in mammalian cells (Veeck and Esteller, 2010). These enzymes act at the cytosine that is in general adjacent to the guanine, converting that to 5-methylcytosine $(5-\mathrm{mC})$. Oncogenic miRNAs are now known to be upregulated via DNA hypomethylation while tumor suppressors are silenced via DNA hypermethylation of $\mathrm{CpG}$ island-associated gene promoters, thereby facilitating the initiation and progression of cancer (Veeck and Esteller, 2010; Suzuki et al., 2013; Morales et al., 2017). Some works have shown the hotspots for miRNA methylation in human chromosomes 1, 2, 9, 11, 16, 17, and 19 (Kunej et al., 2011; Morales et al., 2017). Similarly, a higher than expected proportion of miRNA genes has been found in the $\mathrm{CpG}$ islands susceptible to methylation (Gel et al., 2015). Recent evidence also show that miRNA expression can also be modulated by methylation of other regulatory regions, such as enhancers (Morales et al., 2017). Although CpG islands, are located in the promoters of $60 \%$ of the protein coding genes in human genome, the frequency of human miRNA gene methylation is higher than the protein-encoding genes (Weber et al., 2007).

The common types of histone modifications are lysine $(\mathrm{K})$ acetylation and lysine methylation. While lysine acetylation mediated by histone acetyltransferases (HAT) usually uncoils the chromatin structure and enhance transcription activation, deacetylation mediated by histone deacetylases (HDAC) removes the acetyl groups provoking chromatin condensation and gene inactivation. Lysine methylation might generate different effects on gene expression depending on the position and degree of methylation. Methylation at H3K4, K36 and K79 has been associated with gene activation, whereas methylation at $\mathrm{H} 3 \mathrm{~K} 9$, $\mathrm{H} 3 \mathrm{~K} 27$ and H4K20 has been correlated with transcriptional repression (Zhou et al., 2011; Tessarz and Kouzarides, 2014; Romani et al., 2018).

miR-101 is down regulated in GB and it has been shown to reverse CPEB1 (hypomethylation gene) promoter methylation status by regulating the methylation-related histones $\mathrm{H} 3 \mathrm{~K} 27 \mathrm{me} 3$, $\mathrm{H} 3 \mathrm{~K} 4 \mathrm{me} 2, \mathrm{H} 4 \mathrm{~K} 20 \mathrm{me} 3$, and $\mathrm{H} 3 \mathrm{~K} 9 \mathrm{me} 3$ in $\mathrm{GB}$ ( $\mathrm{Li}$ and $\mathrm{Wu}$, 2017). Similarly, methylation-associated silencing of miR-34c has been shown to promote self-renewal and epithelial-mesenchymal transition in breast tumor- initiating cells (Yu et al., 2012). Moreover, DNA methylation and/or EZH2-mediated histone methylation were recently confirmed to contribute to miR31 loss in TNBC (Augoff et al., 2012). Elsewhere, miR-155 has been shown to be epigenetically repressed by wild-type gene BRCA1 through its interaction with HDAC2 resulting in deacetylation of $\mathrm{H} 2 \mathrm{~A}$ and $\mathrm{H} 3$ on the miR-155 promoter in normal breast tissues (Chang et al., 2011). JARID1B demethylase has been shown to contribute to breast cancer cell proliferation through the epigenetic repression (removing the active mark H3K4me3) of let-7e a tumor suppressor miRNA. Additionally, JARID1B can also repress miR-1246, miR-1826 and miR-3615p (Mitra et al., 2011). Similarly, a study using PCa cells identified miR-615 as an epigenetically activated miRNA through the loss of DNA methylation and gain of $\mathrm{H} 3 \mathrm{~K} 9$ acetylation (Hulf et al., 2011). As it is beyond the scope of this review to exhaust all the epigenetic mechanisms that regulate the progression of cancers and miRNA dysregulation, detailed explanations have been summarized by Rennie and Nelson (1999), Liu et al. (2013), Suzuki et al. (2013), Dai et al. (2014), Fang et al. (2014), Karsli-Ceppioglu et al. (2014), Morales et al. (2017), and Ruggero et al. (2018).

\section{Protein-Coding Genes Modifications and Cancer Aggressiveness}

The accumulation of genetic mutations has been considered the major cause of neoplasia (Hanahan and Weinberg, 2011) whose path is relatively straightforward: mutation of tumor suppressors and/or oncogenes causing either the loss or gain of functions and abnormal expression (You and Jones, 2012).

Recently, gene expression profiles have been translated into clinical applications either as prognostic or predictive signatures in cancer. A study using pathway and machine learning based methods found a 35-gene expression signature that can discriminate between rapidly- and slowly progressing GB and its prognostic value (Fatai and Gamieldien, 2018). Similarly, a 21gene assay, Oncotype DX, has been used to predict likelihood of recurrence in women with ER positive breast cancer (Paik et al., 2004; Goldstein et al., 2008). Gene expression analysis using MammaPrint Symphony, a 70-gene panel, enables a fairly dynamic assessment of neoplastic process, allowing categorizing breast cancer patients according to the high or low risk for relapse (van 't Veer et al., 2002; Bueno-de-Mesquita et al., 2009).

Several genetic lesions including TP53, EGFR and PTEN mutations have long been identified in GB (Brennan et al., 2013). Sequencing of over 20,000 genes discovered an extended number of altered protein coding sequences including IDH1 (isocitrate dehydrognase) that were altered in more than $10 \%$ of GB (Parsons et al., 2008). Additionally, mutations in IDH1 are a hallmark molecular feature of secondary GB as compared to primary GB. Its occurrence is found in approximately $70 \%$ of secondary GB and 5$20 \%$ of primary GB (Ichimura et al., 2009; Yan et al., 2009). The O(6)-methylguanine-DNA methyltransferase (MGMT), a DNA repair enzyme, whose frequency of MGMT promoter methylation has been shown to range from 30\% to $60 \%$ in GB (Weller et al., 2010), is an independent favorable prognostic factor. Patients with methylated MGMT promoter tumors have a survival benefit when treated with Temozolomide (TMZ) (Hegi et al., 2005). TERT promoter mutations have been found in GBs where patients with TERT promoter mutations alone (i.e., no IDH mutation) were found to have the poorest overall survival (Killela et al., 2013).

Persistent infection with high-risk human papilloma virus (HPV) entails an increased risk for development of CC (Walboomers et al., 1999). Functional loss of the tumor suppressor p53 by alterations in its TP53 gene is a frequent event in CC (Tommasino et al., 2003). Association of the viral oncoprotein E6 with the tumor suppressor p53 leads to degradation of p53 with subsequent inhibition of the transcriptional regulatory activities of the p53 protein (Thomas et al., 1999). Similarly, association of viral oncoprotein E7 with $\mathrm{pRb}$, retinoblastoma tumor suppressor, also promotes 
the degradation of $\mathrm{pRb}$ (Jones et al., 1997) and disrupts the capacity of $\mathrm{pRb}$ to bind and inactivate functional cellular E2F transcription factors (Chellappan et al., 1992). A study using single-nucleotide polymorphism analysis, identified the IFNG, TMC6/8 (transmembrane channel-like 6 and 8) genes to be associated with CC progression (Wang et al., 2010).

A meta-analysis study has shown that mutations in the genes encoding glutathione S-transferase (GSTP1 and GSTM1) and G158A polymorphism in prostate-specific antigen gene have been associated with an increased risk for PCa (Gong et al., 2012). Similarly, BRCA1/2 mutations confer a more aggressive PCa phenotype with a higher probability of nodal involvement, distant metastasis and poor survival outcome in patients (Castro et al., 2013). Furthermore, high PSCA expression, expressed in the basal cells of normal prostate and in more than $80 \%$ of $\mathrm{PCa}$, has been correlated with higher stage, metastasis, and poor outcome ( $\mathrm{Gu}$ et al., 2000). Germline mutations in HOXB13 is associated with a significantly increased risk of hereditary PCa (Ewing et al., 2012). Equally important, deletion of the tumor suppressor gene encoding the PTEN has been described in more than two-thirds of patients with advanced/aggressive PCa. Genomic PTEN loss is associated with tumor progression and poor prognosis (Yoshimoto et al., 2007) and with increased risk of recurrence after prostatectomy for clinically localized PCa (Chaux et al., 2012).

A proportion of all breast cancers can be explained by the inheritance of germline mutations in one of the two major breast cancer susceptibility genes BRCA1 and BRCA2 related to DNA repair mechanisms (Claus et al., 1996; Martin and Weber, 2000). Similarly mutations in genes encoding other proteins that are involved in DNA repair expose patients to an elevated risk for breast cancer. In this sense, rare germline mutations in RAD51C a gene involved in the recombinational repair of double-stranded DNA breaks (Meindl et al., 2010) and in the ATM gene (Thompson et al., 2005), the cell cycle CHEK2 gene (Robson, 2009) have been shown to confer increased risks of breast cancer (Collins, 2011). Additionally, rare mutations in the PTEN (on chromosome 10) (Nelen et al., 1996) and STK11 (Boardman et al., 1998) genes associated with Cowden and Peutz-Jeghers syndromes, respectively, have been associated with an increased risk of breast cancer.

More information on known cancer susceptibility genes and regions have been summarized by Parsons et al. (2008), Li et al. (2016), and Bhargava et al. (2017) for GB (Bahrami et al., 2018; Tan et al., 2018) for CC (Collins, 2011; Michailidou et al., 2015) for BC, and (Martinez-Gonzalez et al., 2018; Benafif and Eeles, 2016) for PCa.

In conclusion, genetic alterations in the protein-coding genes play a huge role in the tumorigenesis of aggressive cancers where majority of these genes are potentially regulated also by epigenetically mechanisms, such as miRNAs. The pieces of evidence presented above are also in agreement that miRNAs play crucial roles in tumorigenesis and that epigenetic mechanisms play a major role in own miRNA dysregulation. Consequently, all these interwined mechanisms lead to cancer aggressiveness.

\section{HYPOXIA MICROENVIRONMENT}

Hypoxia, low level of oxygen, is a fundamentally important phenomenon of solid tumors and specifically, intratumoral hypoxia is an important driving force for cancer progression that leads to patient mortality (Harris, 2002; Vaupel et al., 2004; Kulshreshtha et al., 2007). Hypoxic response is essentially mediated by hypoxia inducible factor-1alpha (HIF-1 $\alpha$ ) induced under conditions of low oxygen in a nuclear factor- $\kappa \mathrm{B}$ dependent manner (Jiang et al., 1997). At normal oxygen tension, HIF- $1 \alpha$ is hydroxylated in the oxygen-dependent degradation domain (ODDD) by prolyl hydroxylases (PHD) and after recognized by the von Hippel-Lindau (VHL) protein and consequently ubiquitinated and selected for degradation by proteasome. This process is inhibited during hypoxia (Huang et al., 1996) where stabilized HIF- $1 \alpha$ subunits heterodimerize with $\beta$ - subunits to form the active HIF-1 complex that consequently activates gene transcription by binding to the HRE; 5'-RCGTG-3' in promoters and enhancers of target genes (Semenza, 1999).

HIF-1 regulates the transcription of hundreds of genes in response to hypoxia (Manalo et al., 2005; Elvidge et al., 2006) among which are glucose transporters, glycolytic enzymes, growth factors and genes involved in gluconeogenesis, highenergy phosphate and haem metabolism, erythropoiesis, iron transportation, vasomotor regulation and nitric oxide synthesis (Ratcliffe et al., 1998; Semenza, 2000; Greijer et al., 2005). Although HIF-1 usually induces pro survival (CA9, SLC2A1 and VEGF) genes, a role of HIF-1 in regulation of apoptosis has also been described. HIF-1 promotes cell death through an increase in p53 or other proapoptotic proteins like BCL2/adenovirus E1B $19 \mathrm{kDa}$-interacting protein 3 (BNIP3) (Schmid et al., 2004). This dual function of HIF-1 $\alpha$ has been shown to maintain a dynamic balance in overall cell growth and survival (Koshiji and Huang, 2004).

\section{Role of Hypoxia in Cancer Aggressiveness}

There are a number of mechanisms through which hypoxia promotes tumor malignancy including; resistance to radioand chemotherapy (Harris, 2002; Harrison and Blackwell, 2004), increased cell migration and invasion (Fu et al., 2010), reprogramming toward a cancer stem cell (CSC) phenotype and expansion of CSC populations (Heddleston et al., 2009). HIF-1 promotes cell survival in low oxygen conditions by activating the transcription of prosurvival genes (Semenza, 2000) (Figure 2). Moreover, HIF-1 represses E-cadherin expression leading to loss of cell-cell adhesion and epithelial-mesenchymal transformation (EMT) through the expression of the transcriptional repressors ZFHX1A, ZFHX1B, and TCF3 (Krishnamachary et al., 2003) and motility through expression of c-MET (Pennacchietti et al., 2003). HIFs regulate the expression and activity of EMT main transcription factors such as Twist, Snail, Slug, Sip1 (Smad interacting protein 1), and zinc finger E-box-binding homeobox 1 (ZEB1) (Jiang et al., 2011). Epigenetic programming can regulate EMT, and 
EMT may be reversed by dynamic epigenetic modifications (Huangyang and Shang, 2013). Chen and co-workers showed that DNA methylation regulates Snail and Slug genes transcription. The treatment with 5-aza-2'-deoxycytidine, an inhibitor of DNMT, can induce expression of Snail and Slug genes (Chen et al., 2013). Similarly, HIF-1 controls invasion through the expression of matrix metalloproteinase 2, urokinase plasminogen activator receptor and lysyl oxidase (Krishnamachary et al., 2003; Erler et al., 2006). Furthermore, hypoxia has been shown to activate pSTAT signaling and thereby increasing the secretion of immunosuppressive cytokines such as CSF1 and CCL2, which are useful in inhibiting T-cell proliferation and macrophage phagocytosis, which in turn accelerate tumor progression (Wei et al., 2011).

HIF-1 expression has been correlated with tumor grade in gliomas, with the highest expression found in high-grade gliomas like GB (Søndergaard et al., 2002). Pseudopalisading necrosis and vascular proliferation observed in GB tumors is a manifestation of hypoxia and represent tumor cells migrating away from vasoocclusive, distorted and degenerating blood vessels of the tumor center. As tumor growth is dependent on the formation of new blood vessels, they are often highly vascularized. However, the vasculature is poorly organized and exhibits severe structural and functional abnormalities. Consequently, this leads to regions of the tumor experiencing a reduced supply of oxygen, known as hypoxic regions (Folkman, 1971; Vaupel et al., 2004). Elevated HIF- $1 \alpha$ in glioma cells have been shown to cause an increase in the expression of VEGF and CXC chemokine ligand (Jain et al., 2007) both of which promote angiogenesis through different mechanisms, eventually leading to the formation of the malformed vessels, thus leading to a vicious cycle that promotes GB tumor growth and aggressiveness (Würth et al., 2014). Similarly, HIF-1 has also been shown to promote angiogenesis through stromal-derived factor 1 (SDF-1) (Iliopoulos et al., 1996; Krishnamachary et al., 2003).

Twistl is a basic-helix-loop-helix transcription factor which has been shown to acts as a key regulator of EMT and to promote tumor invasion and metastasis (Jung and Yang, 2015). In this sense, a study that investigated the change of Twistl expression in human cervical squamous cancer cell line ( $\mathrm{SiHa})$ after hypoxia treatment observed that, hypoxia treatment elevated the expression of Twist 1 in $\mathrm{SiHa}$ cells. Knockdown of Twistl with siRNA increased the radiosensitivity of SiHa cells under hypoxia condition, accompanied by reduced levels of nuclear Epidermal growth factor receptor (EGFR) and DNA-dependent protein kinase (DNA-PK) (Xiong et al., 2017). Inhibiting the expression of Twist1 could reverse hypoxia-mediated EMT effectively (Sun et al., 2009).

Similarly, hypoxia is a common feature of PCa where hypoxic markers and hypoxia-associated molecules have been associated with a poor prognosis (Stewart et al., 2010). Several reports suggest that hypoxia increases the potential of both resistance and malignancy of PCa (Movsas et al., 2002; Carnell et al., 2006; Milosevic et al., 2007; Vergis et al., 2008). Elsewhere, a study demonstrated an upregulation of the expression a prosurvival gene involved in $\mathrm{pH}$ regulation, carbonic anhydrase 9 (CA IX), in three different PCa cell lines namely, PCa-3, Du145 and LNCaP under hypoxia (Fiaschi et al., 2013).

Additionally, TNBC cells can grow, survive, induce metabolic reprogramming and apoptosis, alter cell adhesion and motility to facilitate metastasis and resistance to chemotherapy under hypoxic conditions (Semenza, 2001; Muz et al., 2015). A study done using (MDA-MB-231) TNBC cells showed a translational activation of Integrin beta 3 (ITGB3) under hypoxia and that ITGB3 regulated malignant features, including EMT and cell migration, through the TGF- $\beta$ pathway (Sesé et al., 2017). Also, hypoxia has been shown to represses the expression of many DNA repair genes including the tumor suppressor gene - BRCA1, which has the important role in preventing the formation of breast cancer (Scanlon and Glazer, 2015). Increased adipose tissue hypoxia can establish a pro-malignancy environment in breast tissues. This was shown by a study that co-cultured human SGBS adipocytes with ER-positive MCF7 breast cancer cells for $24 \mathrm{~h}$ and later observed increased expression levels of the EMT-inducing transcription factors FOXC2 and Twist1 (Yao-Borengasser et al., 2015). Additionally, histone demethylase (JMJD2C) has been shown to selectively interact with HIF-1 $\alpha$, but not HIF- $2 \alpha$. Subsequently, JMJD2C decreases trimethylation of histone $\mathrm{H} 3$ at lysine 9, and enhances HIF-1 binding to hypoxia response elements, thereby activating transcription of genes encoding proteins involved in metabolic reprogramming for the tumor growth and lung metastasis in breast cancer (Luo et al., 2012).

Although many evidences presented above have been done using cancer cell lines and animal models, clinical evidences also show that HIF- $1 \alpha$ accumulation, a factor upregulated during hypoxia, to be associated with poor patient survival in patients with early stage CC (Birner et al., 2000) and lymph node-positive breast cancer (Schindl et al., 2002). Elsewhere an increase in the level of HIF- $1 \alpha$ has been shown to correspond with the pathologic stages of breast cancer. Specifically, higher HIF-1 $\alpha$ expression was found in poorly differentiated lesions than in the corresponding type of well-differentiated lesions demonstrating that increased levels of HIF- $1 \alpha$ are potentially associated with more aggressive tumors (Bos et al., 2001). Significant associations between HIF$2 \alpha$ overexpression and increased patient mortality have been reported for astrocytoma (Khatua et al., 2003).

Based on these studies, it's clear that hypoxia leads to an upregulation of hypoxia inducible factor culminating in the activation of pro-survival genes or pathways that may help the cancer to acquire a more aggressive phenotype.

\section{The microRNAs and the Hypoxia Microenvironment}

As mentioned earlier, miRNAs regulate the majority of eukaryotic genes and the genes related to hypoxia microenvironment are not an exception. miR-210 is an oncogenic miRNA and a target of HIF-1 and -2 (Gee et al., 2014) whose correlation with hypoxia is a biological phenomenon associated with tumor aggressiveness. It has been shown that during hypoxia, miR-210 targets the mRNA that encodes the mitochondrial electron transport chain component protein succinate dehydrogenase complex subunit $\mathrm{D}$ 
(SDHD). Decreased expression of SDHD results in an increased stabilization of HIF1 $\alpha$ and cancer cell survival (Puisségur et al., 2011; Rupaimoole and Slack, 2017). Elsewhere, miR-210 has been shown to downregulate the hypoxia stress response cell death inducer mitochondrion-associated 3 (AIFM3), thereby promoting survival of cancer cells (Wang J. et al., 2014) and ephrin A3, a hypoxia-responsive angiogenesis inhibitor, leading to increased tumor angiogenesis (Fasanaro et al., 2008).

Likewise, HIF-1 $\alpha$ subunit, is negatively regulated by the VHL tumor suppressor (Harris, 2002) and miR-155 has been shown to downregulate the expression of VHL tumor suppressor, a protein involved in the cellular response to hypoxia. Additionally, downregulation of VHL has been shown to lead to increased angiogenesis and facilitate cancer cell survival (Kong et al., 2014). Elsewhere, miR-21-5p and miR-23b-3p are also reported to target VHL and decrease the production of the VHL protein, that results to upregulation of vascular endothelial growth factor A (VEGFA) expression (Chen L. et al., 2012; Zhang et al., 2014). In the same sense, miR-7-5p downregulates the expression of $O$-linked $N$-acetylglucosamine transferase (OGT), leading to decreased expression of vascular endothelial growth factor receptor 2 (VEGFR2) (Babae et al., 2014). Notably, overexpression of miR128 has been shown to downregulate the activity of p70S6K1 and the expression of its downstream signaling molecules such as HIF-1 and VEGF resulting in reduced cell proliferation, tumor growth and angiogenesis (Shi et al., 2012).

In addition, the hypoxic microenvironment also influences the biogenesis of several miRNAs. In this sense, Drosha, a component of miRNA biogenesis, has been reported to be downregulated in response to tumor hypoxia through a process mediated by the direct binding of the hypoxia-responsive transcription factors ETS1 and ELK1 to the promoter of DROSHA (Rupaimoole and Slack, 2017). Similarly, Dicer has been shown to be downregulated through direct targeting of the DICER 3' UTR by miRNAs such as miR-103/107 (Martello et al., 2010), let-7 (Tokumaru et al., 2008) and miR-630 (Rupaimoole et al., 2016) where tumor hypoxia further influenced these effects. Additionally, downregulation of DICER expression by epigenetic mechanisms, which are mediated by the hypoxia-induced inhibition of the oxygen-dependent H3K27me3 demethylases KDM6A and KDM6B (van den Beucken et al., 2014), have also been reported.

Table 1 shows a list of miRNAs deregulated under hypoxia microenvironment in the four cancers previously mentioned. Some of the genes involved include VEGFA (angiogenesis) (Yue et al., 2012), WNT1 (proliferation), ERBB3 (proliferation) (Tang et al., 2016), SMAD4 (tumor suppressor) (Phuah et al., 2017), NDRG2 (radioresistance) (Wang W. et al., 2016) and EGFR (invasiveness) (Rupaimoole and Slack, 2017) all leading to tumor aggressiveness. Evidently, there is a connection between miRNAs and hypoxia but further studies are needed.

\section{THE CANCER STEM-LIKE STATE}

Cancer stem-like cells, also known as tumor-initiating cells or tumor-propagating cells, are a subpopulation of tumor cells that selectively possess tumor-initiation and self-renewal capacity and the ability to give rise to bulk populations of nontumorigenic cancer cell progeny through differentiation. They propagate tumors phenotypically similar to the parental tumor (Chen J. et al., 2012).

\section{The Stem-Like State and Cancer Aggressiveness}

Tumors comprise a heterogeneous cell population, with $0.1-0.8 \%$ of these tumor cells being cancer stem cells (Konrad et al., 2017). CSCs share similar features with the normal stem cells such as expression of the stem cell markers, capacity for self-renewal and long term proliferation, formation of tumor sphere among others. In contrast, solid cancer stem cells differ from normal stem cells in frequency, proliferation, aberrant expression of differentiation markers, chromosomal abnormalities and tumor formation (Reya et al., 2001; Nimmakayala et al., 2018). CSCs have been implicated in the initiation, progression, maintenance and recurrence of tumors in a variety of cancers (Reya et al., 2001; Singh et al., 2004; Vander Griend et al., 2008; Yi et al., 2008; Tu and Lin, 2012; Xie et al., 2016). The potent tumor initiation of cancer stem cells together with their radioresistance (Debeb et al., 2009), and chemoresistance (Li et al., 2008) suggests that these cells contribute to tumor aggressiveness (Figure 2).

Epigenetic mechanisms have been shown to play a role in the pathogenesis of CSCs (Shukla and Meeran, 2014; Li and Li, 2015). Specifically, DNA methylation plays an important role in the loss of pluripotency and developmental plasticity in cells. In addition, CSCs can be generated from epigenetic reprogramming where specific genes of stem cells recover their expression, while specific genes for differentiation are downregulated (Shukla and Meeran, 2014). The $\mathrm{Wnt} / \beta$-catenin pathway plays important functions in self-renewal and differentiation of CSCs (Hoffmeyer et al., 2012). DNA methylation has been linked to aberrant Wnt/ $\beta$-catenin pathway activation through the enhanced promoter methylation and subsequent silencing of various Wnt inhibitors such as WIF1, AXIN2, SFRP-1 and DKK1 in breast cancers (Klarmann et al., 2008). Activation of EMT can confer cells with CSC and tumorinitiating properties (Morel et al., 2008) and loss of membrane protein E-cadherin is a hallmark of EMT. DNA methylation of E-cadherin promoter has been shown to help recruit HDACs to the site, leading to histone deacetylation and its transcriptional silencing (Wang and Shang, 2013). Transcriptionally active chromatin marked by $\mathrm{H} 3 \mathrm{~K} 9 \mathrm{Ac}$ has been shown to be reinforced by $\mathrm{H} 3 \mathrm{~K} 4$ methylation ( $\mathrm{H} 3 \mathrm{~K} 4 \mathrm{me} 3)$ and $\mathrm{H} 3 \mathrm{~K} 9$ hyperacetylation to induce the expression of OCT4 and Nanog to maintain selfrenewal (Chen and Daley, 2008). Likewise, CD44, CD133 and Musashi-1 promoters presented a hypomethylated status which was associated with high expression of CSC markers in TNBC (Kagara et al., 2012). The studies discussed above are selected examples illustrating how epigenetic mechanisms control the transcription control of CSC in various malignancies. Aberrant epigenetic mechanisms may transform normal stem cells to cancer stem cells with the loss of differentiation capacity and the acquisition of stem-like phenotypes that help to maintain malignant growth. 
In addition, different clinical studies have sought to link the presence of cancer stem cell-like state to cancer development, progression and patient prognosis. A study by Tao et al. comparing the levels of expression of cancer stem cell-state markers ALDH1, CD117 and CD133 in 52 ovarian cancer patients showed that increased levels of these markers were significantly associated with higher tumor grade (Tao et al., 2018). Another study retrospectively analyzed serum samples from 140 patients for the expression of CD44 and ALDH1, the major markers of stem cell state in breast cancer. They found out that patients with a higher expression of CD44 had a significantly shorter overall survival and progression free survival compared to those with lower expression (Kong et al., 2018). In CC, a study analyzing the samples of 139 patients found a correlation between a low expression of P16INK4A, a blocker of stem cell self renewal ability, and high expression of ALDH1 with poor outcomes in patients treated with radiotherapy with/without chemotherapy (Fu et al., 2018). This was in agreement with another study by Lin et al. that showed the over expression of P16INK4A was correlated with better prognosis in CC by down regulating reprogramming of cells into the stem cell state (Lin et al., 2014). Other studies have shown variable associations of cancer stem cell state markers with progression of different cancers. For example, the expression of CD133 and CD44 in GB patients was shown to be negatively correlated with the survival time (Metellus et al., 2010; Pietras et al., 2014). Similarly, a study found OCT4 to be over-expressed in CC tissues as compared to the adjacent normal tissues. Moreover, high OCT4 expression was positively associated with radiotherapy resistance and an independent risk factor for CC (Yang et al., 2014). Likewise, an immunohistochemistry analysis study, aiming to compare the expression of Nanog in patients with CC and cervical dysplasia in 235 patients with various degrees of cervical epithelial lesions, found significantly higher expression of Nanog in CC than in cervical dysplasia and higher in cervical dysplasia than in normal cervical epithelia (Ye et al., 2008). Therefore, these studies provide evidences for the clinical relevance of CSCs.

\section{The Stem-Like State and Hypoxia}

Low oxygen tension is associated with maintenance of an undifferentiated cell state and it has been shown to promote the self-renewal of embryonic stem (ES) cells and prevent the differentiation of stem cells in vitro (Parmar et al., 2007; Clarke and van der Kooy, 2009; Silván et al., 2009). Several studies have shown that restricted oxygen conditions expand the fraction of cells positive for cancer stem cell markers (Tavaluc et al., 2007; Das et al., 2008; McCord et al., 2009). In this sense, a study done by Heddleston and group demonstrated that extended exposure to hypoxia can result in a phenotypic shift in the non-stem population to mirror that of the stem-like subset and promote cell growth and self-renewal. They also found out that non-stem cells cultured under hypoxia were able to form oncospheres at twice the rate of control cells in normoxia. Moreover, following long term-culture (10-14 days) of nonstem cells in hypoxia, the OCT4, Nanog and c-Myc displayed significant and consistent increase in T4121 non-stem glioma cells as compared to normoxia (Heddleston et al., 2009).

Similarly, a study observed that CSCs under hypoxic conditions displayed an increased VEGF expression relative to the non-stem cells. In addition, CSCs specifically regulated several targets (HIF-2 $\alpha$ and transcriptional targets of HIF-2 $\alpha$ :

TABLE 1 | microRNAs associated with hypoxia and the stem-like state in four aggressive cancers.

\begin{tabular}{lll}
\hline Cancer & Hypoxia & Stem-like state \\
\hline Glioblastoma & miR-205-5p, miR-210, miR-21-5p miR-23b- & miR-125b, miR-33a, miR-34 miR-10b, \\
& $3 p$, miR-7-5p & miR-143, miR-330, miR-582-5p, miR-363, \\
& & miR-138, miR-153, miR-124, miR-9, \\
& miR-128 miR-218, miR-146-a miR-326
\end{tabular}

Reference

Godlewski et al., 2008; Kefas et al., 2009; Li Y. et al., 2009; Li Z. et al., 2009; Guessous et al., 2010, 2013; Shi et al., 2010; Mei et al., 2011; Chan et al., 2012; Chen L. et al., 2012; Yue et al., 2012; Tan et al., 2012; Lee et al., 2013; Qiu et al., 2013; Tu et al., 2013; Zhao et al., 2013a,b; Babae et al., 2014; Floyd et al., 2014; Lai et al., 2014; Wang H. et al., 2014; Yao et al., 2014; Zhang et al., 2014

(Phuah et al., 2017; Tang et al., 2016)(Wang et al., 2013, 2017; Zhou X. et al., 2017)

Liu et al., 2015; Liu C. et al., 2017; Chen et al., 2016; Wang W. et al., 2016; Panigrahi et al., 2018; Song et al., 2018

miR-590-5p, miR-181a-5p, miR-30e-5p, miR-34
Choi et al., 2011; Kong et al., 2014; Rupaimoole et al., 2016; Liu K. et al., 2017; Zhou L. et al., 2017

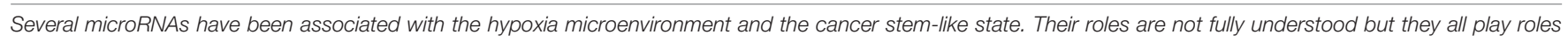
that favor the tumor aggressiveness. miR, microRNAs. 
OCT4, Glut-1 and Serpin B9) under hypoxia to a greater degree than non-stem cells (Li Z. et al., 2009).

In the same sense, a study done by $\mathrm{Li}$ and group, using primary glioma cells, showed that hypoxia maintained the cells in undifferentiated state, slowed their growth by entering into quiescent phase and increased their colony forming efficiency and migration. The cells had elevated expression of stem cells markers and decreased expression of markers associated with differentiation (Li et al., 2013). Similarly, hypoxia has also been shown to increase the expression of stem-like cell markers and to promote clonogenicity in neurospheres from GB (Bar et al., 2010).

Accordingly, expression of HIF-1 $\alpha$, Nanog and OCT4 has been observed in primary PCa tumors, of which, expression of Nanog and OCT3/4 were highly enriched in HIF-1 $\alpha$ positive tumor regions. A different study also suggested SOX2 as a hypoxia-responsive gene that contributes to PCa cell invasion and sphere formation mediated by low oxygen tensions (Bae et al., 2016). Elsewhere, a study done using MDA-MB-231, a representative TNBC cell line, showed an increased proportion of stem cells population and a significantly increased cell colonyformation rate in MDA-MB-231 cells after they were treated with hypoxia (Xie et al., 2016). Similarly, Samanta and colleagues demonstrated that chemotherapy-induced HIF activity enriched the TNBC stem cell population through interleukin-6 and interleukin-8 signaling and increased expression of multidrug resistance 1 . Moreover, they showed that increased expression of HIF- $1 \alpha$ or HIF target genes in breast cancer biopsies was associated with decreased overall survival (Samanta et al., 2014).

There is clear evidence showing hypoxia modulates several types of cancers, however, this topic deserves more attention especially in cervical and breast cancers.

\section{The microRNAs and Cancer Stem-Like State}

There is an established relationship between miRNAs and the cancer stem-like state. In this sense, the EMT-activator ZEB1 is a crucial promoter of metastasis that has been shown to repress the expression of stemness-inhibiting miR-203. Also, the candidate targets of the miR-200 family have been shown to be stem cell factors, such as SOX2 and KLF4. Moreover, the miR-200c, miR-203, and miR-183 have been shown to suppress the expression of stem-like cell factors in cancer cells and mouse embryonic stem (ES) cells, by targeting the polycomb repressor Bmil (Wellner et al., 2009).

Glioblastoma stem-like cells (GSCs) share some characteristics with normal neural stem-like cells, such as expression of neural stem cell markers, capacity for self-renewal and long-term proliferation, formation of neurospheres and the ability for multilineage differentiation into nervous system lineages (neurons, astrocytes and oligodendrocytes) (Vescovi et al., 2006). In GSCs obtained from human U251, miR-125b was the first miRNA found to be downregulated and shown to play a role in GSC maintenance (Shi et al., 2010; Zhao et al., 2014). Since then, several others miRNAs have been related with stem-like state feature in GB. For example, overexpression of miR-33a in non- GSC glioblastoma cells promoted the display of features associated with GSCs, suggesting that this miRNA contributed directly to the GSC phenotype (Wang H. et al., 2014). Elsewhere, suppression of reprogramming by miR-34a was due, at least in part, to repression of pluripotency genes, including Nanog, SOX2 and Mycn (N-Myc). A different study also showed that miR-34a directly inhibits the expression of Notch-1, Notch2 and c-Met in GSCs (Li Y. et al., 2009; Guessous et al., 2013). Additionally, miR-10b is upregulated in human GB and GSC lines and its inhibition strongly reduces the proliferation, invasion and migration of GSCs. Moreover, miR-10b inhibition has been shown to significantly decrease the growth of GSCderived orthotopic GB xenografts (Guessous et al., 2013).

Elsewhere, over-expression of miR-143 was shown to inhibit glycolysis, promote differentiation, and decrease the tumorigenic capacity of GSCs in vivo, highlighting its important role as a tumor suppressor (Zhao et al., 2013b). OncomiR-138 has been identified as part of a molecular signature and prognostic biomarker of GSCs (Chan et al., 2012). Similarly, miR-330, miR-582-5p, and miR-363 have been shown to promote GSC migration and invasion by reducing apoptosis (Floyd et al., 2014; Yao et al., 2014). Also, transient transfection of miR153 into GSCs was shown to impair their self-renewal ability and induce their differentiation. Moreover, miR-153 could also repress tumor stem cell growth and induce apoptosis (Zhao et al., 2013a). The transcription factor, SOX2, is essential for maintaining stem cell self-renewal and pluripotency and is a direct target of miR-124 therefore, miR-124 has been shown to decrease the migration of GB cells and inhibit self-renewal of GSCs by targeting SOX2 (Lee et al., 2013). Several other miRNAs that regulate proliferation, self-renewal and migration of GSCs have been described, including miR-9 (Tan et al., 2012), miR-128 (Godlewski et al., 2008), miR-218 (Tu et al., 2013), miR-146-a (Mei et al., 2011), and miR-326 (Kefas et al., 2009) miR-21 is regarded as an onco-miR in GB and its over-expression has been associated to poor prognosis. Surprisingly, the pro-differentiation role of miR-21 over-expression in GSCs has been shown (Zhi et al., 2010). In this regard, findings from a study demonstrated that the involvement of $\mathrm{miR}-21$ in the positive regulation of differentiation of GSCs suggested that miR-21 inhibition could increase the stemness, a probable source of tumor relapses after GB treatment (Aldaz et al., 2013) (Table 1).

ALDH1A1, intracellular enzyme with detoxifying role, has been identified as cancer stem cells marker for CC (Douville et al., 2009). In this regard, a study showed that miR-23b was downregulated in Hela and CaSki cervical cancer stem cells (CCSCs) derived from tumor spheres and that miR-23b directly binds to the $3^{\prime}$ UTR of ALDH1A1 to suppress its translation. Importantly, targeted expression of miR-23b was shown to disrupt the stemness of CCSCs while miR-23b inhibition increased the population of cervical tumor spheres (Wang et al., 2017). The miR-145 has been shown to induce the differentiation of CSC by down-regulating the stem cell transcription factors that maintain CSC pluripotency. In this sense, high expression of miR-145 indicates a good prognosis in CC patients and a therapeutic target (Zhou X. et al., 2017). The transcription factor OCT4 has also been shown to directly induce the expression of miR-125b, by 
inhibiting its direct target, BAK1, leading to suppression of CC cell apoptosis (Wang et al., 2013).

Accordingly, miR-141 also suppresses prostate cancer stem cells (PCaSCs) and its metastasis by targeting a cohort of prometastasis genes (Liu C. et al., 2017). Elsewhere, a study found out that miR-1301-3p promoted the expansion of PCaSCs by targeting the inhibitors of Wnt pathway, GSK3 $\beta$ and SFRP1, and consequently activating the pathway (Song et al., 2018). Another pathway explored for PCaSCs maintenance is the suppression of p27, caused for instance, by increased miR-150 expression, that might participate in the development and progression of PCaSCs (Liu et al., 2015). It has also been shown that downregulation of miR-34c in cancer stem cells causes recurrence of PCa (Chen et al., 2016).

Regarding breast cancer, Zhou and team showed that miR590-5p inhibited BC cells stemness through targeting SOX2 and they suggested that miR-590-5p might be a useful strategy for BC treatment (Zhou L. et al., 2017). Also, shRNA-mediated knockdown of SOX2 has been shown to inhibit BC cell expansion and migration followed by a significant reduction in the levels of miR-181a-5p and miR-30e-5p. Moreover, overexpression of these two miRNAs resulted in a reduced protein level of the tumor suppressor candidate 3 (TUSC3) in BC cells. Consequently, mutations of the potential binding sites in the $3^{\prime}$-UTR of TUSC3 abrogated the inhibitory effects of the miRNAs (Liu K. et al., 2017). Elsewhere, a study done by Choi et al. (2011), identified miR-34 as a p53 target that plays an essential role in restraining somatic reprogramming and genetic ablation of miR-34a promoted iPSC generation without compromising selfrenewal or differentiation (Choi et al., 2011) (Table 1).

Therefore, miRNA based therapy targeting CSCs has the potential to allow more effective treatment strategies in the future.

\section{miRNAs, Hypoxia and Stem-Like State and Future Therapy Prospects}

The main aim of miRNA therapeutic modulation is to design molecules that can inhibit or mimic mature miRNAs effectively in order to reverse the loss or gain of miRNA function. Based on this concept, targeting miRNAs overexpressed in cancer or re-expressing those downregulated in cancer represents an optimal approach and both the stem-like state and the hypoxia microenvironment might be a target as well.

The inability to reduce the HIF-1 levels during prolonged hypoxia leads to cell death, making this a potential therapeutic target in cancer. To escape this death during continuous oxygen depletion, cells pass the signal from HIF-1 to HIF-2 and eventually to HIF-3 thus allowing them the ability to promote angiogenesis and long-term survival through a process known as the HIF switch (Serocki et al., 2018). Importantly, miRNAs can regulate the HIF switch during hypoxia making them important therapeutic targets (Serocki et al., 2018). In this sense, a study showed an upregulation of a miR-18a after $24 \mathrm{~h}$ in hypoxia a direct target of HIF1A mRNA (Jiang, 2015) suggesting its ability to induce to the HIF switch. Elsewhere, miRNA-mediated beta subunits suppression has been shown to limit HIF-1 activity and angiogenesis providing a novel, alpha subunit-independent mechanism for HIF signaling regulation (Yamakuchi et al., 2010; Deng et al., 2016). In human CC (HeLa) cells, miR-147 has been shown to reduce the levels of HIF-3 isoform, a dominant-negative regulator of HIF-1, in turn stabilizing HIF-1 accumulation (Wang F. et al., 2016).

Moreover, HIF-1 $\alpha$ is activated in normal neural progenitors and is present in both CSC and non stem-like cells at more severely hypoxic conditions $(\leq 1 \%)$ limiting its value in terms of therapeutic targeting (Li Z. et al., 2009). However, HIF- $2 \alpha$ offers hope as a therapeutic target in GB in that it is practically absent in non-glioma stem-like cells and specifically elevated in GSCs, even under modest hypoxic conditions (Carmeliet and Jain, 2000; Cárdenas-Navia et al., 2008; Li Z. et al., 2009). The regulation of HIF2 $\alpha$ is not a general stem cell phenomenon as normal neural progenitors express essentially no HIF2 $\alpha$ mRNA or protein.

Besides this, many HIF inhibitor molecules have been identified (Xia et al., 2012; Serocki et al., 2018) but none of the presently available inhibitors appears to disrupt the HIF1 pathway exclusively consequently resulting to regulation of a wide range cellular metabolic activities (Rodriguez et al., 2016). However, recent efforts has been made to develop selective HIF-2 inhibitors that are now in clinical studies (Wallace et al., 2016).

The development of therapies against CSCs is challenging because both bulk cancer cells and CSCs must be eliminated and so far it has proven difficult. Similarly, CSC-targeted therapy may damage normal stem/progenitor cells and block the regeneration of normal tissues, causing tissue or organ dysfunction (Huang and Rofstad, 2017). However, cell based delivery of miRNAs or miRNA inhibitors offer a promising approach as it can abolish CSCs by modulating their function and/or expression of important proteins to at least that of non-CSCs. Therefore as discussed under 'stem-like cells and miRNAs' section, the same miRNAs implicated in the regulation of the CSC properties can be targeted using miRNA modulation studies to reverse the cancer stem cell fate.

As epigenetic mechanisms have important functions in modulating miRNA expression, cancer progression and stem cell properties in cancer cells, targeting components of these epigenetic pathways would help in reversing this fate. A summary of these epigenetic drugs and their clinical status can be found in Toh et al. (2017). Similarly clinical trials using miRNAs as therapeutic targets have been summarized by Chakraborty et al. (2017) and Rupaimoole and Slack (2017). Specifically, MRX34 (Mirna Therapeutics) have completed a multicentre phase I trial by using miR-34 mimic to target multiple solid tumors (ClinicalTrials.gov identifier NCT01829971).

Although many important questions regarding miRNAs biological function, target specificity, stability, safety, efficacy and effective delivery remain to be addressed, the possibility that miRNAs or their specific target protectors can be used in future therapeutic approaches, to reverse the loss and gain of functions, to regulate the hypoxic HIF switch, to regulate hypoxic microenvironment and stem cell reprogramming, emphasizes the importance of the interconnect relationship between the miRNAs, hypoxia and stem-like state to the cancer aggressiveness. 


\section{CONCLUSION}

Tumor therapy resistance, invasiveness and poor patient survival are features shared by several aggressive cancers. The miRNAs, hypoxia, hypoxia inducible factors and the stem-like state all play key roles in contributing to the cancer aggressiveness. Importantly, miRNAs are often found dysregulated in various tumors such as glioblastoma, breast, prostate, and cervical cancers where they regulate several processes and pathways contributing to tumorigenesis angiogenesis, growth, infiltration and resistance. Several miRNAs have been shown to play critical roles in the interactions between the tumor and the tumor microenvironment and specifically, they regulate several key genes and signaling pathways that lead to adaptation of the cancer cell in hypoxic conditions. In like manner, hypoxia regulates a set of miRNAs commonly referred as HRMs and even influences the biogenesis of miRNAs. This interaction between miRNAs and hypoxia or HIFs can account for many vital events relevant to tumorigenesis such as angiogenesis, metabolism, apoptosis, cell cycle regulation, proliferation, metastasis, stemness and resistance to anticancer therapy. Both hypoxia and the miRNAs have similarly been implicated in the maintenance of CSCs that drive the tumor propagation ability and contributes to the tumor resistance. Therefore, based on the evidence covered in this review, it is possible to conclude that miRNAs, hypoxia and the stem-like state play a connected role, like a feedback loop or a complex signaling network in promoting tumor aggressiveness and future miRNA targeted therapies should factor in these concepts.

\section{REFERENCES}

Aldaz, B., Sagardoy, A., Nogueira, L., Guruceaga, E., Grande, L., Huse, J. T., et al. (2013). Involvement of miRNAs in the differentiation of human glioblastoma multiforme stem-like cells. PLoS One 8:e77098. doi: 10.1371/journal.pone. 0077098

Alexander, R. P., Fang, G., Rozowsky, J., Snyder, M., and Gerstein, M. B. (2010) Annotating non-coding regions of the genome. Nat. Rev. Genet. 11, 559-571. doi: $10.1038 / \mathrm{nrg} 2814$

Arpino, G., Milano, M., and De Placido, S. (2015). Features of aggressive breast cancer. Breast 24, 594-600. doi: 10.1016/j.breast.2015.06.001

Augoff, K., McCue, B., Plow, E. F., and Sossey-Alaoui, K. (2012). miR-31 and its host gene lncRNA LOC554202 are regulated by promoter hypermethylation in triple-negative breast cancer. Mol. Cancer 11:5. doi: 10.1186/1476-4598-11-5

Babae, N., Bourajjaj, M., Liu, Y., Van Beijnum, J. R., Cerisoli, F., Scaria, P. V., et al. (2014). Systemic miRNA-7 delivery inhibits tumor angiogenesis and growth in murine xenograft glioblastoma. Oncotarget 5, 6687-6700. doi: 10.18632/ oncotarget.2235

Bae, K. M., Dai, Y., Vieweg, J., and Siemann, D. W. (2016). Hypoxia regulates SOX2 expression to promote prostate cancer cell invasion and sphere formation. Am. J. Cancer Res. 6, 1078-1088.

Bahrami, A., Hasanzadeh, M., Shahidsales, S., Farazestanian, M., Hassanian, S. M., Moetamani Ahmadi, M., et al. (2018). Genetic susceptibility in cervical cancer: from bench to bedside. J. Cell. Physiol. 233, 1929-1939. doi: 10.1002/jcp.26019

Bao, S., Wang, X., Wang, Z., Yang, J., Liu, F., and Yin, C. (2018). MicroRNA-30 mediates cell invasion and metastasis in breast cancer. Biochem. Cell Biol. 96, 825-831. doi: 10.1139/bcb-2018-0032

Bar, E. E., Lin, A., Mahairaki, V., Matsui, W., and Eberhart, C. G. (2010). Hypoxia increases the expression of stem-cell markers and promotes clonogenicity in glioblastoma neurospheres. Am. J. Pathol. 177, 1491-1502. doi: 10.2353/ajpath. 2010.091021

\section{AUTHOR CONTRIBUTIONS}

All authors conceptualized, wrote, edited and critically evaluated the manuscript, and also approved the final version of the manuscript. LM prepared the final version of the manuscript. VF and VM-N supervised the work.

\section{FUNDING}

This study was supported by the Brazilian agencies Conselho Nacional de Desenvolvimento Científico e Tecnológico (CNPq), Coordenação de Aperfeiçoamento de Pessoal de Nível Superior (CAPES), Fundação de Amparo à Pesquisa do Rio de Janeiro (FAPERJ), Pró-Saúde Associação Beneficente de Assistência Social e Hospitalar, and Ary Frauzino Foundation for Cancer Research.

\section{ACKNOWLEDGMENTS}

We are thankful to the African Academy of Sciences (AAS) for the endless support and the continued mentorship. This opportunity was as a result of the collaboration that exist between AAS and the Brazilian Academy of Sciences and for that we are grateful. We would also like to thank Carlos Eduardo Pilotto Heming for helping with the image design.

Bartel, D. P. (2009). MicroRNAs: target recognition and regulatory functions. Cell 136, 215-233. doi: 10.1016/j.cell.2009.01.002

Benafif, S., and Eeles, R. (2016). Genetic predisposition to prostate cancer. Br. Med. Bull. 120, 75-89. doi: 10.1093/bmb/ldw039

Bernstein, E., Caudy, A. A., Hammond, S. M., and Hannon, G. J. (2001). Role for a bidentate ribonuclease in the initiation step of RNA interference. Nature 409, 363-366. doi: 10.1038/35053110

Bhargava, S., Patil, V., Mahalingam, K., and Somasundaram, K. (2017). Elucidation of the genetic and epigenetic landscape alterations in RNA binding proteins in glioblastoma. Oncotarget 8, 16650-16668. doi: 10.18632/oncotarget. 14287

Birner, P., Schindl, M., Obermair, A., Plank, C., Breitenecker, G., and Oberhuber, G. (2000). Overexpression of hypoxia-inducible factor lalpha is a marker for an unfavorable prognosis in early-stage invasive cervical cancer. Cancer Res. 60, 4693-4696.

Boardman, L. A., Thibodeau, S. N., Schaid, D. J., Lindor, N. M., McDonnell, S. K., Burgart, L. J., et al. (1998). Increased risk for cancer in patients with the PeutzJeghers syndrome. Ann. Intern. Med. 128, 896-899. doi: 10.7326/0003-4819128-11-199806010-00004

Bohnsack, M. T., Czaplinski, K., and Gorlich, D. (2004). Exportin 5 is a RanGTP-dependent dsRNA-binding protein that mediates nuclear export of pre-miRNAs. RNA 10, 185-191. doi: 10.1261/rna.5167604

Borchert, G. M., Lanier, W., and Davidson, B. L. (2006). RNA polymerase III transcribes human microRNAs. Nat. Struct. Mol. Biol. 13, 1097-1101. doi: 10. 1038/nsmb1167

Bos, R., Zhong, H., Hanrahan, C. F., Mommers, E. C., Semenza, G. L., Pinedo, H. M., et al. (2001). Levels of hypoxia-inducible factor-1 alpha during breast carcinogenesis. J. Natl. Cancer Inst. 93, 309-314. doi: 10.1093/jnci/93.4.309

Brennan, C. W., Verhaak, R. G. W., McKenna, A., Campos, B., Noushmehr, H., Salama, S. R., et al. (2013). The somatic genomic landscape of glioblastoma. Cell 155, 462-477. doi: 10.1016/j.cell.2013.09.034 
Bueno-de-Mesquita, J. M., Linn, S. C., Keijzer, R., Wesseling, J., Nuyten, D. S. A., van Krimpen, C., et al. (2009). Validation of 70-gene prognosis signature in node-negative breast cancer. Breast Cancer Res. Treat. 117, 483-495. doi: 10. 1007/s10549-008-0191-2

Calin, G. A., Sevignani, C., Dumitru, C. D., Hyslop, T., Noch, E., Yendamuri, S., et al. (2004). Human microRNA genes are frequently located at fragile sites and genomic regions involved in cancers. Proc. Natl. Acad. Sci. U.S.A. 101, 2999-3004. doi: 10.1073/pnas.0307323101

Cárdenas-Navia, L. I., Mace, D., Richardson, R. A., Wilson, D. F., Shan, S., and Dewhirst, M. W. (2008). The pervasive presence of fluctuating oxygenation in tumors. Cancer Res. 68, 5812-5819. doi: 10.1158/0008-5472.CAN-07-6387

Carmeliet, P., and Jain, R. K. (2000). Angiogenesis in cancer and other diseases. Nature 407, 249-257. doi: $10.1038 / 35025220$

Carnell, D. M., Smith, R. E., Daley, F. M., Saunders, M. I., Bentzen, S. M., and Hoskin, P. J. (2006). An immunohistochemical assessment of hypoxia in prostate carcinoma using pimonidazole: implications for radioresistance. Int. J. Radiat. Oncol. Biol. Phys. 65, 91-99. doi: 10.1016/j.ijrobp.2005. 11.044

Carthew, R. W., and Sontheimer, E. J. (2009). Origins and mechanisms of miRNAs and siRNAs. Cell 136, 642-655. doi: 10.1016/j.cell.2009.01.035

Castro, E., Goh, C., Olmos, D., Saunders, E., Leongamornlert, D., Tymrakiewicz, M., et al. (2013). Germline BRCA mutations are associated with higher risk of nodal involvement, distant metastasis, and poor survival outcomes in prostate cancer. J. Clin. Oncol. 31, 1748-1757. doi: 10.1200/JCO.2012.43.1882

Chakraborty, C., Sharma, A. R., Sharma, G., Doss, C. G. P., and Lee, S.-S. (2017). Therapeutic miRNA and siRNA: moving from bench to clinic as next generation medicine. Mol. Ther. Nucleic Acids 8, 132-143. doi: 10.1016/j.omtn. 2017.06.005

Chan, X. H. D., Nama, S., Gopal, F., Rizk, P., Ramasamy, S., Sundaram, G., et al. (2012). Targeting glioma stem cells by functional inhibition of a prosurvival oncomiR-138 in malignant gliomas. Cell Rep. 2, 591-602. doi: 10.1016/j.celrep. 2012.07.012

Chang, S., Wang, R.-H., Akagi, K., Kim, K.-A., Martin, B. K., Cavallone, L., et al. (2011). Tumor suppressor BRCA1 epigenetically controls oncogenic microRNA-155. Nat. Med. 17, 1275-1282. doi: 10.1038/nm. 2459

Chaux, A., Peskoe, S. B., Gonzalez-Roibon, N., Schultz, L., Albadine, R., Hicks, J., et al. (2012). Loss of PTEN expression is associated with increased risk of recurrence after prostatectomy for clinically localized prostate cancer. Mod. Pathol. 25, 1543-1549. doi: 10.1038/modpathol.2012.104

Chellappan, S., Kraus, V. B., Kroger, B., Munger, K., Howley, P. M., Phelps, W. C., et al. (1992). Adenovirus E1A, simian virus 40 tumor antigen, and human papillomavirus E7 protein share the capacity to disrupt the interaction between transcription factor E2F and the retinoblastoma gene product. Proc. Natl. Acad. Sci. U.S.A. 89, 4549-4553. doi: 10.1073/pnas.89.10.4549

Chen, J., McKay, R. M., and Parada, L. F. (2012). Malignant glioma: lessons from genomics, mouse models, and stem cells. Cell 149, 36-47. doi: 10.1016/j.cell. 2012.03.009

Chen, L., Han, L., Zhang, K., Shi, Z., Zhang, J., Zhang, A., et al. (2012). VHL regulates the effects of miR-23b on glioma survival and invasion via suppression of HIF-1 $\alpha /$ VEGF and $\beta$-catenin/Tcf-4 signaling. Neuro Oncol. 14, 1026-1036. doi: $10.1093 /$ neuonc/nos122

Chen, L., and Daley, G. Q. (2008). Molecular basis of pluripotency. Hum. Mol. Genet. 17, R23-R27. doi: $10.1093 / \mathrm{hmg} / \mathrm{ddn} 050$

Chen, Y., Rao, Q., Zhang, H., Xu, H., Zhang, C., Zhuang, Q., et al. (2016). miR-34C disrupts the stemness of purified CD133+prostatic cancer stem cells. Urology 96, 177.e1-177.e9. doi: 10.1016/j.urology.2016.07.021

Chen, Y., Wang, K., Qian, C.-N., and Leach, R. (2013). DNA methylation is associated with transcription of Snail and Slug genes. Biochem. Biophys. Res. Commun. 430, 1083-1090. doi: 10.1016/j.bbrc.2012.12.034

Choi, Y. J., Lin, C.-P., Ho, J. J., He, X., Okada, N., Bu, P., et al. (2011). miR-34 miRNAs provide a barrier for somatic cell reprogramming. Nat. Cell Biol. 13, 1353-1360. doi: $10.1038 / \mathrm{ncb} 2366$

Clarke, L., and van der Kooy, D. (2009). Low oxygen enhances primitive and definitive neural stem cell colony formation by inhibiting distinct cell death pathways. Stem Cells 27, 1879-1886. doi: 10.1002/ stem.96
Claus, E. B., Schildkraut, J. M., Thompson, W. D., and Risch, N. J. (1996). The genetic attributable risk of breast and ovarian cancer. Cancer 77, 23182324. doi: 10.1002/(SICI) 1097-0142(19960601)77:11<2318::AID-CNCR21>3. $0 . \mathrm{CO} ; 2-\mathrm{Z}$

Collins, A. (2011). The genetics of breast cancer: risk factors for disease. Appl. Clin. Genet. 4, 11-19. doi: 10.2147/TACG.S13139

Cui, J. G., Zhao, Y., Sethi, P., Li, Y. Y., Mahta, A., Culicchia, F., et al. (2010). Micro-RNA-128 (miRNA-128) down-regulation in glioblastoma targets ARP5 (ANGPTL6), Bmi-1 and E2F-3a, key regulators of brain cell proliferation. J. Neurooncol. 98, 297-304. doi: 10.1007/s11060-009-0077-0

Dai, E., Yu, X., Zhang, Y., Meng, F., Wang, S., Liu, X., et al. (2014). EpimiR: a database of curated mutual regulation between miRNAs and epigenetic modifications. Database 2014:bau023. doi: 10.1093/database/bau023

Das, B., Tsuchida, R., Malkin, D., Koren, G., Baruchel, S., and Yeger, H. (2008). Hypoxia enhances tumor stemness by increasing the invasive and tumorigenic side population fraction. Stem Cells 26, 1818-1830. doi: 10.1634/stemcells.20070724

Debeb, B. G., Xu, W., and Woodward, W. A. (2009). Radiation resistance of breast cancer stem cells: understanding the clinical framework. J. Mammary Gland Biol. Neoplasia 14, 11-17. doi: 10.1007/s10911-009-9114-z

Deng, B., Du, J., Hu, R., Wang, A.-P., Wu, W.-H., Hu, C.-P., et al. (2016), MicroRNA-103/107 is involved in hypoxia-induced proliferation of pulmonary arterial smooth muscle cells by targeting HIF-1 $\beta$. Life Sci. 147, 117-124. doi: 10.1016/j.lfs.2016.01.043

Denli, A. M., Tops, B. B. J., Plasterk, R. H. A., Ketting, R. F., and Hannon, G. J. (2004). Processing of primary microRNAs by the Microprocessor complex. Nature 432, 231-235. doi: 10.1038/nature03049

Di Leva, G., Garofalo, M., and Croce, C. M. (2014). MicroRNAs in cancer. Annu. Rev. Pathol. Mech. Dis. 9, 287-314. doi: 10.1146/annurev-pathol-012513104715

Douville, J., Beaulieu, R., and Balicki, D. (2009). ALDH1 as a functional marker of cancer stem and progenitor cells. Stem Cells Dev. 18, 17-26. doi: 10.1089/scd. 2008.0055

Elvidge, G. P., Glenny, L., Appelhoff, R. J., Ratcliffe, P. J., Ragoussis, J., and Gleadle, J. M. (2006). Concordant regulation of gene expression by hypoxia and 2-oxoglutarate-dependent dioxygenase inhibition: the role of HIF-1alpha, HIF2alpha, and other pathways. J. Biol. Chem. 281, 15215-15226. doi: 10.1074/jbc. M511408200

Erler, J. T., Bennewith, K. L., Nicolau, M., Dornhöfer, N., Kong, C., Le, Q.-T., et al. (2006). Lysyl oxidase is essential for hypoxia-induced metastasis. Nature 440, 1222-1226. doi: $10.1038 /$ nature 04695

Eulalio, A., Tritschler, F., and Izaurralde, E. (2009). The GW182 protein family in animal cells: new insights into domains required for miRNAmediated gene silencing. RNA 15, 1433-1442. doi: 10.1261/rna. 1703809

Ewing, C. M., Ray, A. M., Lange, E. M., Zuhlke, K. A., Robbins, C. M., Tembe, W. D., et al. (2012). Germline mutations in HOXB13 and prostate-cancer risk. N. Engl. J. Med. 366, 141-149. doi: 10.1056/NEJMoa1110000

Fabian, M. R., Sonenberg, N., and Filipowicz, W. (2010). Regulation of mRNA translation and stability by microRNAs. Annu. Rev. Biochem. 79, 351-379. doi: 10.1146/annurev-biochem-060308-103103

Fang, J., Zhang, H., and Jin, S. (2014). Epigenetics and cervical cancer: from pathogenesis to therapy. Tumor Biol. 35, 5083-5093. doi: 10.1007/s13277-014$1737-\mathrm{z}$

Fasanaro, P., D’Alessandra, Y., Di Stefano, V., Melchionna, R., Romani, S., Pompilio, G., et al. (2008). MicroRNA-210 modulates endothelial cell response to hypoxia and inhibits the receptor tyrosine kinase ligand Ephrin-A3. J. Biol. Chem. 283, 15878-15883. doi: 10.1074/jbc.M800731200

Fatai, A. A., and Gamieldien, J. (2018). A 35-gene signature discriminates between rapidly- and slowly-progressing glioblastoma multiforme and predicts survival in known subtypes of the cancer. BMC Cancer 18:377. doi: 10.1186/s12885-0184103-5

Fiaschi, T., Giannoni, E., Taddei, M. L., Cirri, P., Marini, A., Pintus, G., et al. (2013). Carbonic anhydrase IX from cancer-associated fibroblasts drives epithelialmesenchymal transition in prostate carcinoma cells. Cell Cycle 12, 1791-1801. doi: $10.4161 /$ cc. 24902

Floyd, D. H., Zhang, Y., Dey, B. K., Kefas, B., Breit, H., Marks, K., et al. (2014). Novel anti-apoptotic microRNAs 582-5p and 363 promote human glioblastoma 
stem cell survival via direct inhibition of caspase 3, caspase 9, and Bim. PLoS One 9:e96239. doi: 10.1371/journal.pone.0096239

Folkman, J. (1971). Tumor angiogenesis: therapeutic implications. N. Engl. J. Med. 285, 1182-1186. doi: 10.1056/NEJM197111182852108

Fu, H., Luo, F., Yang, L., Wu, W., and Liu, X. (2010). Hypoxia stimulates the expression of macrophage migration inhibitory factor in human vascular smooth muscle cells via HIF-1alpha dependent pathway. BMC Cell Biol. 11:66. doi: 10.1186/1471-2121-11-66

Fu, H.-C., Chuang, I.-C., Yang, Y.-C., Chuang, P.-C., Lin, H., Ou, Y.-C., et al. (2018). Low P16 ${ }^{\mathrm{INK} 4 \mathrm{~A}}$ expression associated with high expression of cancer stem cell markers predicts poor prognosis in cervical cancer after radiotherapy. Int. J. Mol. Sci. 19:E2541. doi: 10.3390/ijms19092541

Gee, H. E., Ivan, C., Calin, G. A., and Ivan, M. (2014). HypoxamiRs and cancer: from biology to targeted therapy. Antioxid. Redox Signal. 21, 1220-1238. doi: 10.1089/ars.2013.5639

Gel, B., Díez-Villanueva, A., Serra, E., Buschbeck, M., Peinado, M. A., and Malinverni, R. (2015). regioneR: an R/Bioconductor package for the association analysis of genomic regions based on permutation tests. Bioinformatics 32, 289-291. doi: 10.1093/bioinformatics/btv562

Godlewski, J., Nowicki, M. O., Bronisz, A., Williams, S., Otsuki, A., Nuovo, G., et al. (2008). Targeting of the Bmi-1 oncogene/stem cell renewal factor by microRNA128 inhibits glioma proliferation and self-renewal. Cancer Res. 68, 9125-9130. doi: 10.1158/0008-5472.CAN-08-2629

Goldstein, L. J., Gray, R., Badve, S., Childs, B. H., Yoshizawa, C., Rowley, S., et al. (2008). Prognostic utility of the 21-gene assay in hormone receptor-positive operable breast cancer compared with classical clinicopathologic features. J. Clin. Oncol. 26, 4063-4071. doi: 10.1200/JCO.2007.14.4501

Gong, M., Dong, W., Shi, Z., Xu, Y., Ni, W., and An, R. (2012). Genetic polymorphisms of GSTM1, GSTT1, and GSTP1 with prostate cancer risk: a meta-analysis of 57 studies. PLoS One 7:e50587. doi: 10.1371/journal.pone. 0050587

Greijer, A. E., van der Groep, P., Kemming, D., Shvarts, A., Semenza, G. L., Meijer, G. A., et al. (2005). Up-regulation of gene expression by hypoxia is mediated predominantly by hypoxia-inducible factor 1 (HIF-1). J. Pathol. 206, 291-304. doi: 10.1002/path.1778

Grishok, A., Pasquinelli, A. E., Conte, D., Li, N., Parrish, S., Ha, I., et al. (2001). Genes and mechanisms related to RNA interference regulate expression of the small temporal RNAs that control C. elegans developmental timing. Cell 106, 23-34. doi: 10.1016/S0092-8674(01)00431-7

Gu, Z., Thomas, G., Yamashiro, J., Shintaku, I. P., Dorey, F., Raitano, A., et al. (2000). Prostate stem cell antigen (PSCA) expression increases with high gleason score, advanced stage and bone metastasis in prostate cancer. Oncogene 19, 1288-1296. doi: 10.1038/sj.onc. 1203426

Guessous, F., Alvarado-Velez, M., Marcinkiewicz, L., Zhang, Y., Kim, J., Heister, S., et al. (2013). Oncogenic effects of miR-10b in glioblastoma stem cells. J. Neurooncol. 112, 153-163. doi: 10.1007/s11060-013-1047-0

Guessous, F., Zhang, Y., Kofman, A., Catania, A., Li, Y., Schiff, D., et al. (2010). microRNA-34a is tumor suppressive in brain tumors and glioma stem cells. Cell Cycle 9, 1031-1036. doi: 10.4161/cc.9.6.10987

Hanahan, D., and Weinberg, R. A. (2011). Hallmarks of cancer: the next generation. Cell 144, 646-674. doi: 10.1016/j.cell.2011.02.013

Harris, A. L. (2002). Hypoxia-a key regulatory factor in tumour growth. Nat. Rev. Cancer 2, 38-47. doi: 10.1038/nrc704

Harrison, L., and Blackwell, K. (2004). Hypoxia and anemia: factors in decreased sensitivity to radiation therapy and chemotherapy? Oncologist 9(Suppl. 5), 31-40. doi: 10.1634/theoncologist.9-90005-31

Heddleston, J. M., Li, Z., McLendon, R. E., Hjelmeland, A. B., and Rich, J. N. (2009). The hypoxic microenvironment maintains glioblastoma stem cells and promotes reprogramming towards a cancer stem cell phenotype. Cell Cycle 8, 3274-3284. doi: 10.4161/cc.8.20.9701

Hegi, M. E., Diserens, A.-C., Gorlia, T., Hamou, M.-F., de Tribolet, N., Weller, M., et al. (2005). MGMT gene silencing and benefit from temozolomide in glioblastoma. N. Engl. J. Med. 352, 997-1003. doi: 10.1056/NEJMoa043331

Hoffmeyer, K., Raggioli, A., Rudloff, S., Anton, R., Hierholzer, A., Del Valle, I., et al. (2012). Wnt/ -catenin signaling regulates telomerase in stem cells and cancer cells. Science 336, 1549-1554. doi: 10.1126/science.1218370

Huang, L. E., Arany, Z., Livingston, D. M., and Bunn, H. F. (1996). Activation of hypoxia-inducible transcription factor depends primarily upon redox-sensitive stabilization of its alpha subunit. J. Biol. Chem. 271, 32253-32259. doi: 10.1074/ jbc. 271.50 .32253

Huang, R., and Rofstad, E. K. (2017). Cancer stem cells (CSCs), cervical CSCs and targeted therapies. Oncotarget 8, 35351-35367. doi: 10.18632/oncotarget. 10169

Huangyang, P., and Shang, Y. (2013). Epigenetic regulation of epithelial to mesenchymal transition. Curr. Cancer Drug Targets 13, 973-985. doi: 10.2174/ 15680096113136660103

Hulf, T., Sibbritt, T., Wiklund, E. D., Bert, S., Strbenac, D., Statham, A. L., et al. (2011). Discovery pipeline for epigenetically deregulated miRNAs in cancer: integration of primary miRNA transcription. BMC Genomics 12:54. doi: 10 . 1186/1471-2164-12-54

Huntzinger, E., and Izaurralde, E. (2011). Gene silencing by microRNAs: contributions of translational repression and mRNA decay. Nat. Rev. Genet. 12, 99-110. doi: 10.1038/nrg2936

Ichimura, K., Pearson, D. M., Kocialkowski, S., Baäcklund, L. M., Chan, R., Jones, D. T. W., et al. (2009). IDH1 mutations are present in the majority of common adult gliomas but rare in primary glioblastomas. Neuro Oncol. 11, 341-347. doi: 10.1215/15228517-2009-025

Iliopoulos, O., Levy, A. P., Jiang, C., Kaelin, W. G., and Goldberg, M. A. (1996). Negative regulation of hypoxia-inducible genes by the von Hippel-Lindau protein. Proc. Natl. Acad. Sci. U.S.A. 93, 10595-10599. doi: 10.1073/pnas.93.20. 10595

Iorio, M. V., and Croce, C. M. (2012). Causes and consequences of microRNA dysregulation. Cancer J. 18, 215-222. doi: 10.1097/PPO.0b013e318250c001

Jain, R. K., di Tomaso, E., Duda, D. G., Loeffler, J. S., Sorensen, A. G., and Batchelor, T. T. (2007). Angiogenesis in brain tumours. Nat. Rev. Neurosci. 8, 610-622. doi: $10.1038 / \mathrm{nrn} 2175$

Jiang, B. H., Zheng, J. Z., Leung, S. W., Roe, R., and Semenza, G. L. (1997). Transactivation and inhibitory domains of hypoxia-inducible factor lalpha. Modulation of transcriptional activity by oxygen tension. J. Biol. Chem. 272, 19253-19260. doi: 10.1074/jbc.272.31.19253

Jiang, J., Tang, Y., and Liang, X. (2011). EMT: a new vision of hypoxia promoting cancer progression. Cancer Biol. Ther. 11, 714-723. doi: 10.4161/cbt.11.8. 15274

Jiang, W. (2015). MicroRNA-18a decreases choroidal endothelial cell proliferation and migration by inhibiting HIF1A expression. Med. Sci. Monit. 21, 1642-1647. doi: 10.12659/MSM.893068

Jones, D. L., Thompson, D. A., and Münger, K. (1997). Destabilization of the RB tumor suppressor protein and stabilization of p53 contribute to HPV type 16 E7-induced apoptosis. Virology 239, 97-107. doi: 10.1006/viro.1997.8851

Jung, H.-Y., and Yang, J. (2015). Unraveling the TWIST between EMT and cancer stemness. Cell Stem Cell 16, 1-2. doi: 10.1016/j.stem.2014.12.005

Kagara, N., Huynh, K. T., Kuo, C., Okano, H., Sim, M. S., Elashoff, D., et al. (2012). Epigenetic regulation of cancer stem cell genes in triple-negative breast cancer. Am. J. Pathol. 181, 257-267. doi: 10.1016/j.ajpath.2012.03.019

Karsli-Ceppioglu, S., Dagdemir, A., Judes, G., Ngollo, M., Penault-Llorca, F., Pajon, A., et al. (2014). Epigenetic mechanisms of breast cancer: an update of the current knowledge. Epigenomics 6, 651-664. doi: 10.2217/epi.14.59

Kartha, R. V., and Subramanian, S. (2014). Competing endogenous RNAs (ceRNAs): new entrants to the intricacies of gene regulation. Front. Genet. 5:8. doi: 10.3389/fgene.2014.00008

Ke, G., Liang, L., Yang, J. M., Huang, X., Han, D., Huang, S., et al. (2013). MiR-181a confers resistance of cervical cancer to radiation therapy through targeting the pro-apoptotic PRKCD gene. Oncogene 32, 3019-3027. doi: 10.1038/onc.2012. 323

Kefas, B., Comeau, L., Floyd, D. H., Seleverstov, O., Godlewski, J., Schmittgen, T., et al. (2009). The neuronal microRNA miR-326 acts in a feedback loop with notch and has therapeutic potential against brain tumors. J. Neurosci. 29, 15161-15168. doi: 10.1523/JNEUROSCI.4966-09.2009

Khatua, S., Peterson, K. M., Brown, K. M., Lawlor, C., Santi, M. R., LaFleur, B., et al. (2003). Overexpression of the EGFR/FKBP12/HIF-2alpha pathway identified in childhood astrocytomas by angiogenesis gene profiling. Cancer Res. 63, 1865-1870.

Killela, P. J., Reitman, Z. J., Jiao, Y., Bettegowda, C., Agrawal, N., Diaz, L. A., et al. (2013). TERT promoter mutations occur frequently in gliomas and a subset of tumors derived from cells with low rates of self-renewal. Proc. Natl. Acad. Sci. U.S.A. 110, 6021-6026. doi: 10.1073/pnas. 1303607110 
Klarmann, G. J., Decker, A., and Farrar, W. L. (2008). Epigenetic gene silencing in the Wnt pathway in breast cancer. Epigenetics 3, 59-63. doi: 10.4161/epi.3.2. 5899

Kong, W., He, L., Richards, E. J., Challa, S., Xu, C.-X., Permuth-Wey, J., et al. (2014). Upregulation of miRNA-155 promotes tumour angiogenesis by targeting VHL and is associated with poor prognosis and triple-negative breast cancer. Oncogene 33, 679-689. doi: 10.1038/onc.2012.636

Kong, Y., Lyu, N., Wu, J., Tang, H., Xie, X., Yang, L., et al. (2018). Breast cancer stem cell markers CD44 and ALDH1A1 in serum: distribution and prognostic value in patients with primary breast cancer. J. Cancer 9, 3728-3735. doi: $10.7150 /$ jca. 28032

Konrad, C. V., Murali, R., Varghese, B. A., and Nair, R. (2017). The role of cancer stem cells in tumor heterogeneity and resistance to therapy. Can. J. Physiol. Pharmacol. 95, 1-15. doi: 10.1139/cjpp-2016-0079

Koshiji, M., and Huang, L. E. (2004). Dynamic balancing of the dual nature of HIF-1alpha for cell survival. Cell Cycle 3, 853-854. doi: 10.4161/cc.3.7.990

Krishnamachary, B., Berg-Dixon, S., Kelly, B., Agani, F., Feldser, D., Ferreira, G., et al. (2003). Regulation of colon carcinoma cell invasion by hypoxia-inducible factor 1. Cancer Res. 63, 1138-1143.

Krol, J., Loedige, I., and Filipowicz, W. (2010). The widespread regulation of microRNA biogenesis, function and decay. Nat. Rev. Genet. 11, 597-610. doi: $10.1038 / \mathrm{nrg} 2843$

Kulshreshtha, R., Ferracin, M., Negrini, M., Calin, G. A., Davuluri, R. V., and Ivan, M. (2007). Regulation of microRNA expression: the hypoxic component. Cell Cycle 6, 1425-1430. doi: 10.4161/cc.6.12.4410

Kunej, T., Godnic, I., Ferdin, J., Horvat, S., Dovc, P., and Calin, G. A. (2011). Epigenetic regulation of microRNAs in cancer: an integrated review of literature. Mutat. Res. 717, 77-84. doi: 10.1016/j.mrfmmm.2011.03.008

Ladewig, E., Okamura, K., Flynt, A. S., Westholm, J. O., and Lai, E. C. (2012). Discovery of hundreds of mirtrons in mouse and human small RNA data. Genome Res. 22, 1634-1645. doi: 10.1101/gr.133553.111

Lai, N.-S., Dong, Q.-S., Ding, H., Miao, Z.-L., and Lin, Y.-C. (2014). MicroRNA-210 overexpression predicts poorer prognosis in glioma patients. J. Clin. Neurosci. 21, 755-760. doi: 10.1016/j.jocn.2013.06.024

Lee, H. K., Finniss, S., Cazacu, S., Bucris, E., Ziv-Av, A., Xiang, C., et al. (2013). Mesenchymal stem cells deliver synthetic microRNA mimics to glioma cells and glioma stem cells and inhibit their cell migration and self-renewal. Oncotarget 4, 346-361. doi: 10.18632/oncotarget.868

Lee, R. C., Feinbaum, R. L., and Ambros, V. (1993). The C. elegans heterochronic gene lin-4 encodes small RNAs with antisense complementarity to lin-14. Cell 75, 843-854. doi: 10.1016/0092-8674(93)90529-Y

Lee, Y., Ahn, C., Han, J., Choi, H., Kim, J., Yim, J., et al. (2003). The nuclear RNase III Drosha initiates microRNA processing. Nature 425, 415-419. doi: 10.1038/nature01957

Lee, Y., Kim, M., Han, J., Yeom, K.-H., Lee, S., Baek, S. H., et al. (2004). MicroRNA genes are transcribed by RNA polymerase II. EMBO J. 23, 4051-4060. doi: 10.1038/sj.emboj.7600385

Li, L., and Li, W. (2015). Epithelial-mesenchymal transition in human cancer: comprehensive reprogramming of metabolism, epigenetics, and differentiation. Pharmacol. Ther. 150, 33-46. doi: 10.1016/j.pharmthera.2015.01.004

Li, P., and Wu, M. (2017). "Epigenetic mechanisms of glioblastoma," in Glioblastoma, ed. S. De Vleeschouwer (Brisbane: Codon Publications), 43-58. doi: 10.15586/codon.glioblastoma.2017.ch3

Li, P., Zhou, C., Xu, L., and Xiao, H. (2013). Hypoxia enhances stemness of cancer stem cells in glioblastoma: an in vitro study. Int. J. Med. Sci. 10, 399-407. doi: 10.7150/ijms.5407

Li, Q.-J., Cai, J.-Q., and Liu, C.-Y. (2016). Evolving molecular genetics of glioblastoma. Chin. Med. J. 129, 464-471. doi: 10.4103/0366-6999.176065

Li, X., Lewis, M. T., Huang, J., Gutierrez, C., Osborne, C. K., Wu, M.-F., et al. (2008). Intrinsic resistance of tumorigenic breast cancer cells to chemotherapy. J. Natl. Cancer Inst. 100, 672-679. doi: 10.1093/jnci/djn123

Li, Y., Guessous, F., Zhang, Y., Dipierro, C., Kefas, B., Johnson, E., et al. (2009). MicroRNA-34a inhibits glioblastoma growth by targeting multiple oncogenes. Cancer Res. 69, 7569-7576. doi: 10.1158/0008-5472.CAN-09-0529

Li, Z., Bao, S., Wu, Q., Wang, H., Eyler, C., Sathornsumetee, S., et al. (2009). Hypoxia-inducible factors regulate tumorigenic capacity of glioma stem cells. Cancer Cell 15, 501-513. doi: 10.1016/j.ccr.2009.03.018
Lima, F. R. S., Kahn, S. A., Soletti, R. C., Biasoli, D., Alves, T., da Fonseca, A. C. C., et al. (2012). Glioblastoma: therapeutic challenges, what lies ahead. Biochim. Biophys. Acta 1826, 338-349. doi: 10.1016/j.bbcan.2012.05.004

Lin, J., Albers, A. E., Qin, J., and Kaufmann, A. M. (2014). Prognostic significance of o/verexpressed p16INK4a in patients with cervical cancer: a meta-analysis. PLoS One 9:e106384. doi: 10.1371/journal.pone.0106384

Liu, C., Liu, R., Zhang, D., Deng, Q., Liu, B., Chao, H.-P., et al. (2017). MicroRNA141 suppresses prostate cancer stem cells and metastasis by targeting a cohort of pro-metastasis genes. Nat. Commun. 8:14270. doi: 10.1038/ncomms 14270

Liu, K., Xie, F., Gao, A., Zhang, R., Zhang, L., Xiao, Z., et al. (2017). SOX2 regulates multiple malignant processes of breast cancer development through the SOX2/miR-181a-5p, miR-30e-5p/TUSC3 axis. Mol. Cancer 16:62. doi: 10. 1186/s12943-017-0632-9

Liu, Z., Wang, J., Li, Y., Fan, J., Chen, L., and Xu, R. (2017). MicroRNA-153 regulates glutamine metabolism in glioblastoma through targeting glutaminase. Tumor Biol. 39:101042831769142. doi: 10.1177/1010428317691429

Liu, D. Z., Zhang, H. Y., Long, X. L., Zou, S. L., Zhang, X. Y., Han, G. Y., et al. (2015). MIR-150 promotes prostate cancer stem cell development via suppressing p27Kip1. Eur. Rev. Med. Pharmacol. Sci. 19, 4344-4352.

Liu, X., Chen, X., Yu, X., Tao, Y., Bode, A. M., Dong, Z., et al. (2013). Regulation of microRNAs by epigenetics and their interplay involved in cancer. J. Exp. Clin. Cancer Res. 32:96. doi: 10.1186/1756-9966-32-96

Luo, W., Chang, R., Zhong, J., Pandey, A., and Semenza, G. L. (2012). Histone demethylase JMJD2C is a coactivator for hypoxia-inducible factor 1 that is required for breast cancer progression. Proc. Natl. Acad. Sci. U.S.A. 109, E3367E3376. doi: 10.1073/pnas.1217394109

Ma, R., Jiang, T., and Kang, X. (2012). Circulating microRNAs in cancer: origin, function and application. J. Exp. Clin. Cancer Res. 31:38. doi: 10.1186/17569966-31-38

Manalo, D. J., Rowan, A., Lavoie, T., Natarajan, L., Kelly, B. D., Ye, S. Q., et al. (2005). Transcriptional regulation of vascular endothelial cell responses to hypoxia by HIF-1. Blood 105, 659-669. doi: 10.1182/blood-2004-07-2958

Martello, G., Rosato, A., Ferrari, F., Manfrin, A., Cordenonsi, M., Dupont, S., et al. (2010). A MicroRNA targeting dicer for metastasis control. Cell 141, 1195-1207. doi: 10.1016/j.cell.2010.05.017

Martin, A. M., and Weber, B. L. (2000). Genetic and hormonal risk factors in breast cancer. J. Natl. Cancer Inst. 92, 1126-1135. doi: 10.1093/jnci/92.14.1126

Martinez-Gonzalez, L. J., Pascual Geler, M., Robles Fernandez, I., Cozar, J. M., Lorente, J. A., and Alvarez Cubero, M. J. (2018). Improving the genetic signature of prostate cancer, the somatic mutations. Urol. Oncol. 36, 312.e17312.e23. doi: 10.1016/j.urolonc.2018.03.012

McCord, A. M., Jamal, M., Shankavaram, U. T., Shankavarum, U. T., Lang, F. F., Camphausen, K., et al. (2009). Physiologic oxygen concentration enhances the stem-like properties of $\mathrm{CD} 133+$ human glioblastoma cells in vitro. Mol. Cancer Res. 7, 489-497. doi: 10.1158/1541-7786.MCR-08-0360

Mei, J., Bachoo, R., and Zhang, C.-L. (2011). MicroRNA-146a inhibits glioma development by targeting Notch1. Mol. Cell. Biol. 31, 3584-3592. doi: 10.1128/ MCB.05821-11

Meindl, A., Hellebrand, H., Wiek, C., Erven, V., Wappenschmidt, B., Niederacher, D., et al. (2010). Germline mutations in breast and ovarian cancer pedigrees establish RAD51C as a human cancer susceptibility gene. Nat. Genet. 42, 410-414. doi: 10.1038/ng.569

Metellus, P., Nanni-Metellus, I., Delfino, C., Colin, C., Coulibaly, B., Fina, F., et al. (2010). Prognostic impact of stem cell marker CD133 in 61 glioblastoma patients treated with concomitant chemoradiation: a prospective study. J. Clin. Oncol. 28(Suppl. 15):2027. doi: 10.1200/jco.2010.28.15_suppl.2027

Michailidou, K., Beesley, J., Lindstrom, S., Canisius, S., Dennis, J., Lush, M. J., et al. (2015). Genome-wide association analysis of more than 120,000 individuals identifies 15 new susceptibility loci for breast cancer. Nat. Genet. 47, 373-380. doi: 10.1038/ng.3242

Milosevic, M., Chung, P., Parker, C., Bristow, R., Toi, A., Panzarella, T., et al. (2007). Androgen withdrawal in patients reduces prostate cancer hypoxia: implications for disease progression and radiation response. Cancer Res. 67, 6022-6025. doi: 10.1158/0008-5472.CAN-07-0561

Mitra, D., Das, P. M., Huynh, F. C., and Jones, F. E. (2011). Jumonji/ARID1 B (JARID1B) protein promotes breast tumor cell cycle progression through 
epigenetic repression of MicroRNA let-7e. J. Biol. Chem. 286, 40531-40535. doi: 10.1074/jbc.M111.304865

Monroig-Bosque, P. D. C., Rivera, C. A., and Calin, G. A. (2015). MicroRNAs in cancer therapeutics: "from the bench to the bedside." Expert Opin. Biol. Ther. 15, 1381-1385. doi: 10.1517/14712598.2015.1074999

Morales, S., Monzo, M., and Navarro, A. (2017). Epigenetic regulation mechanisms of microRNA expression. Biomol. Concepts 8, 203-212. doi: 10.1515/bmc-20170024

Morel, A.-P., Lièvre, M., Thomas, C., Hinkal, G., Ansieau, S., and Puisieux, A. (2008). Generation of breast cancer stem cells through epithelial-mesenchymal transition. PLoS One 3:e2888. doi: 10.1371/journal.pone.0002888

Movsas, B., Chapman, J. D., Hanlon, A. L., Horwitz, E. M., Greenberg, R. E., Stobbe, C., et al. (2002). Hypoxic prostate/muscle pO2 ratio predicts for biochemical failure in patients with prostate cancer: preliminary findings. Urology 60, 634-639. doi: 10.1016/S0090-4295(02)01858-7

Muz, B., de la Puente, P., Azab, F., and Azab, A. K. (2015). The role of hypoxia in cancer progression, angiogenesis, metastasis, and resistance to therapy. Hypoxia 3, 83-92. doi: 10.2147/HP.S93413

Nana-Sinkam, S. P., and Croce, C. M. (2013). Clinical applications for microRNAs in cancer. Clin. Pharmacol. Ther. 93, 98-104. doi: 10.1038/clpt.2012.192

Nelen, M. R., Padberg, G. W., Peeters, E. A. J., Lin, A. Y., van den Helm, B., Frants, R. R., et al. (1996). Localization of the gene for Cowden disease to chromosome 10q22-23. Nat. Genet. 13, 114-116. doi: 10.1038/ng0596-114

Nimmakayala, R. K., Batra, S. K., and Ponnusamy, M. P. (2018). Unraveling the journey of cancer stem cells from origin to metastasis. Biochim. Biophys. Acta 1871, 50-63. doi: 10.1016/j.bbcan.2018.10.006

Paik, S., Shak, S., Tang, G., Kim, C., Baker, J., Cronin, M., et al. (2004). A multigene assay to predict recurrence of tamoxifen-treated, node-negative breast cancer. N. Engl. J. Med. 351, 2817-2826. doi: 10.1056/NEJMoa041588

Palanichamy, J. K., and Rao, D. S. (2014). miRNA dysregulation in cancer: towards a mechanistic understanding. Front. Genet. 5:54. doi: 10.3389/fgene.2014.00054

Panigrahi, G. K., Ramteke, A., Birks, D., Abouzeid, H. E., Venkataraman, S., Agarwal, C., et al. (2018). Exosomal microRNA profiling to identify hypoxiarelated biomarkers in prostate cancer. Oncotarget 9, 13894-13910. doi: 10. 18632/oncotarget. 24532

Parmar, K., Mauch, P., Vergilio, J.-A., Sackstein, R., and Down, J. D. (2007). Distribution of hematopoietic stem cells in the bone marrow according to regional hypoxia. Proc. Natl. Acad. Sci. U.S.A. 104, 5431-5436. doi: 10.1073/ pnas.0701152104

Parsons, D. W., Jones, S., Zhang, X., Lin, J. C.-H., Leary, R. J., Angenendt, P., et al. (2008). An integrated genomic analysis of human glioblastoma multiforme. Science 321, 1807-1812. doi: 10.1126/science.1164382

Peng, X., Guo, W., Liu, T., Wang, X., Tu, X., Xiong, D., et al. (2011). Identification of miRs-143 and -145 that is associated with bone metastasis of prostate cancer and involved in the regulation of EMT. PLoS One 6:e20341. doi: 10.1371/ journal.pone.0020341

Peng, X., Yan, B., and Shen, Y. (2018). MiR-1301-3p inhibits human breast cancer cell proliferation by regulating cell cycle progression and apoptosis through directly targeting ICT1. Breast Cancer 25, 742-752. doi: 10.1007/s12282-0180881-5

Pennacchietti, S., Michieli, P., Galluzzo, M., Mazzone, M., Giordano, S., and Comoglio, P. M. (2003). Hypoxia promotes invasive growth by transcriptional activation of the met protooncogene. Cancer Cell 3, 347-361. doi: 10.1016/ S1535-6108(03)00085-0

Phuah, N. H., Azmi, M. N., Awang, K., and Nagoor, N. H. (2017). Down-regulation of MicroRNA-210 confers sensitivity towards 1'S-1'e-acetoxychavicol acetate (ACA) in cervical cancer cells by targeting SMAD4. Mol. Cells 40, 291-298. doi: 10.14348/molcells.2017.2285

Pietras, A., Katz, A. M., Ekström, E. J., Wee, B., Hallidy, J. J., Pitter, K. L., et al. (2014). Osteopontin-CD44 signaling in the glioma perivascular niche enhances cancer stem cell phenotypes and promotes aggressive tumor growth. Cell Stem Cell 14, 357-369. doi: 10.1016/j.stem.2014.01.005

Puisségur, M.-P., Mazure, N. M., Bertero, T., Pradelli, L., Grosso, S., RobbeSermesant, K., et al. (2011). miR-210 is overexpressed in late stages of lung cancer and mediates mitochondrial alterations associated with modulation of HIF-1 activity. Cell Death Differ. 18, 465-478. doi: 10.1038/cdd.2010.119

Qiu, S., Lin, S., Hu, D., Feng, Y., Tan, Y., and Peng, Y. (2013). Interactions of miR-323/miR-326/miR-329 and miR-130a/miR-155/miR-210 as prognostic indicators for clinical outcome of glioblastoma patients. J. Transl. Med. 11:10. doi: 10.1186/1479-5876-11- 10

Qureshi, I. A., and Mehler, M. F. (2012). Emerging roles of non-coding RNAs in brain evolution, development, plasticity and disease. Nat. Rev. Neurosci. 13, 528-541. doi: 10.1038/nrn3234

Ratcliffe, P. J., O’Rourke, J. F., Maxwell, P. H., and Pugh, C. W. (1998). Oxygen sensing, hypoxia-inducible factor- 1 and the regulation of mammalian gene expression. J. Exp. Biol. 201, 1153-1162.

Rennie, P. S., and Nelson, C. C. (1999). Epigenetic mechanisms for progression of prostate cancer. Cancer Metastasis Rev. 17, 401-409. doi: 10.1023/A: 1006121219097

Reya, T., Morrison, S. J., Clarke, M. F., and Weissman, I. L. (2001). Stem cells, cancer and cancer stem cells. Nature 414, 105-111. doi: 10.1038/3510 2167

Robson, M. (2009). CHEK2, breast cancer, and the understanding of clinical utility. Clin. Genet. 78, 8-10. doi: 10.1111/j.1399-0004.2010.01444.x

Rodriguez, J., Pilkington, R., Garcia Munoz, A., Nguyen, L. K., Rauch, N., Kennedy, S., et al. (2016). Substrate-Trapped interactors of PHD3 and FIH cluster in distinct signaling pathways. Cell Rep. 14, 2745-2760. doi: 10.1016/j. celrep.2016.02.043

Romani, M., Pistillo, M. P., and Banelli, B. (2018). Epigenetic targeting of glioblastoma. Front. Oncol. 8:448. doi: 10.3389/fonc.2018.00448

Ruby, J. G., Jan, C. H., and Bartel, D. P. (2007). Intronic microRNA precursors that bypass Drosha processing. Nature 448, 83-86. doi: 10.1038/nature05983

Ruggero, K., Farran-Matas, S., Martinez-Tebar, A., and Aytes, A. (2018). Epigenetic regulation in prostate cancer progression. Curr. Mol. Biol. Rep. 4, 101-115. doi: 10.1007/s40610-018-0095-9

Rupaimoole, R., Ivan, C., Yang, D., Gharpure, K. M., Wu, S. Y., Pecot, C. V., et al. (2016). Hypoxia-upregulated microRNA-630 targets Dicer, leading to increased tumor progression. Oncogene 35, 4312-4320. doi: 10.1038/onc.20 15.492

Rupaimoole, R., and Slack, F. J. (2017). MicroRNA therapeutics: towards a new era for the management of cancer and other diseases. Nat. Rev. Drug Discov. 16, 203-222. doi: 10.1038/nrd.2016.246

Samanta, D., Gilkes, D. M., Chaturvedi, P., Xiang, L., and Semenza, G. L. (2014). Hypoxia-inducible factors are required for chemotherapy resistance of breast cancer stem cells. Proc. Natl. Acad. Sci. U.S.A. 111, E5429-E5438. doi: 10.1073/ pnas. 1421438111

Sana, J., Faltejskova, P., Svoboda, M., and Slaby, O. (2012). Novel classes of noncoding RNAs and cancer. J. Transl. Med. 10:103. doi: 10.1186/1479-5876-10103

Scanlon, S. E., and Glazer, P. M. (2015). Multifaceted control of DNA repair pathways by the hypoxic tumor microenvironment. DNA Repair 32, 180-189. doi: 10.1016/j.dnarep.2015.04.030

Schindl, M., Schoppmann, S. F., Samonigg, H., Hausmaninger, H., Kwasny, W., Gnant, M., et al. (2002). Overexpression of hypoxia-inducible factor 1alpha is associated with an unfavorable prognosis in lymph node-positive breast cancer. Clin. Cancer Res. 8, 1831-1837.

Schmid, T., Zhou, J., and Brüne, B. (2004). HIF-1 and p53: communication of transcription factors under hypoxia. J. Cell. Mol. Med. 8, 423-431. doi: 10.1111/ j.1582-4934.2004.tb00467.x

Semenza, G. L. (1999). Regulation of mammalian O2 homeostasis by hypoxiainducible factor 1. Annu. Rev. Cell Dev. Biol. 15, 551-578. doi: 10.1146/annurev. cellbio.15.1.551

Semenza, G. L. (2000). HIF-1: mediator of physiological and pathophysiological responses to hypoxia. J. Appl. Physiol. 88, 1474-1480. doi: 10.1152/jappl.2000. 88.4.1474

Semenza, G. L. (2001). Hypoxia-inducible factor 1: oxygen homeostasis and disease pathophysiology. Trends Mol. Med. 7, 345-350. doi: 10.1016/S1471-4914(01) 02090-1

Serocki, M., Bartoszewska, S., Janaszak-Jasiecka, A., Ochocka, R. J., Collawn, J. F., and Bartoszewski, R. (2018). miRNAs regulate the HIF switch during hypoxia: a novel therapeutic target. Angiogenesis 21, 183-202. doi: 10.1007/s10456-0189600-2

Sesé, M., Fuentes, P., Esteve-Codina, A., Béjar, E., McGrail, K., Thomas, G., et al. (2017). Hypoxia-mediated translational activation of ITGB3 in breast cancer cells enhances TGF- $\beta$ signaling and malignant features in vitro and in vivo. Oncotarget 8, 114856-114876. doi: 10.18632/oncotarget.23145 
Shi, L., Wang, Z., Sun, G., Wan, Y., Guo, J., and Fu, X. (2014). miR-145 inhibits migration and invasion of glioma stem cells by targeting ABCG2. Neuromolecular Med. 16, 517-528. doi: 10.1007/s12017-014-8305-y

Shi, L., Zhang, J., Pan, T., Zhou, J., Gong, W., Liu, N., et al. (2010). MiR-125b is critical for the suppression of human U251 glioma stem cell proliferation. Brain Res. 1312, 120-126. doi: 10.1016/j.brainres.2009.11.056

Shi, X.-B., Xue, L., Ma, A.-H., Tepper, C. G., Kung, H.-J., and White, R. W. (2011). miR-125b promotes growth of prostate cancer xenograft tumor through targeting pro-apoptotic genes. Prostate 71, 538-549. doi: 10.1002/pros.21270

Shi, Z., Wang, J., Yan, Z., You, Y., Li, C., Qian, X., et al. (2012). MiR-128 inhibits tumor growth and angiogenesis by targeting p70S6K1. PLoS One 7:e32709. doi: 10.1371/journal.pone.0032709

Shukla, S., and Meeran, S. M. (2014). Epigenetics of cancer stem cells: pathways and therapeutics. Biochim. Biophys. Acta 1840, 3494-3502. doi: 10.1016/j.bbagen. 2014.09.017

Silván, U., Díez-Torre, A., Arluzea, J., Andrade, R., Silió, M., and Aréchaga, J. (2009). Hypoxia and pluripotency in embryonic and embryonal carcinoma stem cell biology. Differentiation 78, 159-168. doi: 10.1016/j.diff.2009. 06.002

Singh, S. K., Hawkins, C., Clarke, I. D., Squire, J. A., Bayani, J., Hide, T., et al. (2004). Identification of human brain tumour initiating cells. Nature 432, 396-401. doi: $10.1038 /$ nature 03128

Small, W., Bacon, M. A., Bajaj, A., Chuang, L. T., Fisher, B. J., Harkenrider, M. M., et al. (2017). Cervical cancer: a global health crisis. Cancer 123, 2404-2412. doi: $10.1002 /$ cncr.30667

Søndergaard, K. L., Hilton, D. A., Penney, M., Ollerenshaw, M., and Demaine, A. G. (2002). Expression of hypoxia-inducible factor 1alpha in tumours of patients with glioblastoma. Neuropathol. Appl. Neurobiol. 28, 210-217. doi: 10.1046/j. 1365-2990.2002.00391.x

Song, X.-L., Huang, B., Zhou, B.-W., Wang, C., Liao, Z.-W., Yu, Y., et al. (2018). miR-1301-3p promotes prostate cancer stem cell expansion by targeting SFRP1 and GSK3ß. Biomed. Pharmacother. 99, 369-374. doi: 10.1016/j.biopha.2018.01. 086

Standart, N., and Jackson, R. J. (2007). MicroRNAs repress translation of m7Gppp-capped target mRNAs in vitro by inhibiting initiation and promoting deadenylation. Genes Dev. 21, 1975-1982. doi: 10.1101/gad.1591507

Stewart, G. D., Ross, J. A., McLaren, D. B., Parker, C. C., Habib, F. K., and Riddick, A. C. P. (2010). The relevance of a hypoxic tumour microenvironment in prostate cancer. BJU Int. 105, 8-13. doi: 10.1111/j.1464-410X.2009.08921.x

Sun, S., Ning, X., Zhang, Y., Lu, Y., Nie, Y., Han, S., et al. (2009). Hypoxia-inducible factor-1alpha induces Twist expression in tubular epithelial cells subjected to hypoxia, leading to epithelial-to-mesenchymal transition. Kidney Int. 75, 1278-1287. doi: 10.1038/ki.2009.62

Suzuki, H., Maruyama, R., Yamamoto, E., and Kai, M. (2013). Epigenetic alteration and microRNA dysregulation in cancer. Front. Genet. 4:258. doi: 10.3389/fgene. 2013.00258

Tan, M. S., Chang, S.-W., Cheah, P. L., and Yap, H. J. (2018). Integrative machine learning analysis of multiple gene expression profiles in cervical cancer. PeerJ 6:e5285. doi: 10.7717/peerj.5285

Tan, X., Wang, S., Yang, B., Zhu, L., Yin, B., Chao, T., et al. (2012). The CREB-miR-9 negative feedback minicircuitry coordinates the migration and proliferation of glioma cells. PLoS One 7:e49570. doi: 10.1371/journal.pone.004 9570

Tang, X.-L., Lin, L., Song, L.-N., and Tang, X.-H. (2016). Hypoxia-inducible miR-152 suppresses the expression of WNT1 and ERBB3, and inhibits the proliferation of cervical cancer cells. Exp. Biol. Med. 241, 1429-1437. doi: 10. $1177 / 1535370215610442$

Tao, Y., Li, H., Huang, R., Mo, D., Zeng, T., Fang, M., et al. (2018). Clinicopathological and prognostic significance of cancer stem cell markers in ovarian cancer patients: evidence from 52 studies. Cell. Physiol. Biochem. 46, 1716-1726. doi: 10.1159/000489586

Tavaluc, R. T., Hart, L. S., Dicker, D. T., and El-Deiry, W. S. (2007). Effects of low confluency, serum starvation and hypoxia on the side population of cancer cell lines. Cell Cycle 6, 2554-2562. doi: 10.4161/cc.6.20.4911

Tessarz, P., and Kouzarides, T. (2014). Histone core modifications regulating nucleosome structure and dynamics. Nat. Rev. Mol. Cell Biol. 15, 703-708. doi: $10.1038 / \mathrm{nrm} 3890$
Thomas, M., Pim, D., and Banks, L. (1999). The role of the E6-p53 interaction in the molecular pathogenesis of HPV. Oncogene 18, 7690-7700. doi: 10.1038/sj. onc. 1202953

Thompson, D., Duedal, S., Kirner, J., McGuffog, L., Last, J., Reiman, A., et al. (2005). Cancer risks and mortality in heterozygous ATM mutation carriers. J. Natl. Cancer Inst. 97, 813-822. doi: 10.1093/jnci/dji141

Toh, T. B., Lim, J. J., and Chow, E. K.-H. (2017). Epigenetics in cancer stem cells. Mol. Cancer 16:29. doi: 10.1186/s12943-017-0596-9

Tokumaru, S., Suzuki, M., Yamada, H., Nagino, M., and Takahashi, T. (2008). let-7 regulates Dicer expression and constitutes a negative feedback loop. Carcinogenesis 29, 2073-2077. doi: 10.1093/carcin/bgn187

Tommasino, M., Accardi, R., Caldeira, S., Dong, W., Malanchi, I., Smet, A., et al. (2003). The role of TP53 in Cervical carcinogenesis. Hum. Mutat. 21, 307-312. doi: 10.1002/humu.10178

Torres, A., Torres, K., Paszkowski, T., Jodłowska-Jêdrych, B., Radomański, T., Książek, A., et al. (2011). Major regulators of microRNAs biogenesis Dicer and Drosha are down-regulated in endometrial cancer. Tumor Biol. 32, 769-776. doi: 10.1007/s13277-011-0179-0

Treiber, T., Treiber, N., and Meister, G. (2012). Regulation of microRNA biogenesis and function. Thromb. Haemost. 107, 605-610. doi: 10.1160/TH11-120836

Tu, S.-M., and Lin, S.-H. (2012). Prostate cancer stem cells. Clin. Genitourin. Cancer 10, 69-76. doi: 10.1016/j.clgc.2012.01.002

Tu, Y., Gao, X., Li, G., Fu, H., Cui, D., Liu, H., et al. (2013). MicroRNA-218 inhibits glioma invasion, migration, proliferation, and cancer stem-like cell self-renewal by targeting the polycomb group gene Bmil. Cancer Res. 73, 6046-6055. doi: 10.1158/0008-5472.CAN-13-0358

van den Beucken, T., Koch, E., Chu, K., Rupaimoole, R., Prickaerts, P., Adriaens, M., et al. (2014). Hypoxia promotes stem cell phenotypes and poor prognosis through epigenetic regulation of DICER. Nat. Commun. 5:5203. doi: 10.1038/ncomms6203

van 't Veer, L. J., Dai, H., van de Vijver, M. J., He, Y. D., Hart, A. A. M., Mao, M., et al. (2002). Gene expression profiling predicts clinical outcome of breast cancer. Nature 415, 530-536. doi: 10.1038/415530a

Vander Griend, D. J., Karthaus, W. L., Dalrymple, S., Meeker, A., DeMarzo, A. M., and Isaacs, J. T. (2008). The role of CD133 in normal human prostate stem cells and malignant cancer-initiating cells. Cancer Res. 68, 9703-9711. doi: 10.1158/0008-5472.CAN-08-3084

Vaupel, P., Mayer, A., and Höckel, M. (2004). Tumor hypoxia and malignant progression. Methods Enzymol. 381, 335-354. doi: 10.1016/S0076-6879(04) 81023-1

Veeck, J., and Esteller, M. (2010). Breast cancer epigenetics: from DNA methylation to microRNAs. J. Mammary Gland Biol. Neoplasia 15, 5-17. doi: 10.1007/ s10911-010-9165-1

Vergis, R., Corbishley, C. M., Norman, A. R., Bartlett, J., Jhavar, S., Borre, M., et al. (2008). Intrinsic markers of tumour hypoxia and angiogenesis in localised prostate cancer and outcome of radical treatment: a retrospective analysis of two randomised radiotherapy trials and one surgical cohort study. Lancet Oncol. 9, 342-351. doi: 10.1016/S1470-2045(08)70076-7

Vescovi, A. L., Galli, R., and Reynolds, B. A. (2006). Brain tumour stem cells. Nat. Rev. Cancer 6, 425-436. doi: 10.1038/nrc1889

Walboomers, J. M. M., Jacobs, M. V., Manos, M. M., Bosch, F. X., Kummer, J. A., Shah, K. V., et al. (1999). Human papillomavirus is a necessary cause of invasive cervical cancer worldwide. J. Pathol. 189, 12-19. doi: 10.1002/(SICI) 1096-9896(199909)189:1<12::AID-PATH431>3.0.CO;2-F

Wallace, E. M., Rizzi, J. P., Han, G., Wehn, P. M., Cao, Z., Du, X., et al. (2016). A small-molecule antagonist of HIF $2 \alpha$ is efficacious in preclinical models of renal cell carcinoma. Cancer Res. 76, 5491-5500. doi: 10.1158/0008-5472.CAN16-0473

Wang, F., Zhang, H., Xu, N., Huang, N., Tian, C., Ye, A., et al. (2016). A novel hypoxia-induced miR-147a regulates cell proliferation through a positive feedback loop of stabilizing HIF-1 $\alpha$. Cancer Biol. Ther. 17, 790-798. doi: 10. 1080/15384047.2016.1195040

Wang, W., Liu, M., Guan, Y., and Wu, Q. (2016). Hypoxia-responsive Mir301a and Mir-301b promote radioresistance of prostate cancer cells via downregulating NDRG2. Med. Sci. Monit. 22, 2126-2132. doi: 10.12659/MSM. 896832 
Wang, H., Sun, T., Hu, J., Zhang, R., Rao, Y., Wang, S., et al. (2014). miR-33a promotes glioma-initiating cell self-renewal via PKA and NOTCH pathways. J. Clin. Invest. 124, 4489-4502. doi: 10.1172/JCI75284

Wang, J., Zhao, J., Shi, M., Ding, Y., Sun, H., Yuan, F., et al. (2014). Elevated expression of miR-210 predicts poor survival of cancer patients: a systematic review and meta-analysis. PLoS One 9:e89223. doi: 10.1371/journal.pone. 0089223

Wang, S. S., Gonzalez, P., Yu, K., Porras, C., Li, Q., Safaeian, M., et al. (2010). Common genetic variants and risk for HPV persistence and progression to cervical cancer. PLoS One 5:e8667. doi: 10.1371/journal.pone.0008667

Wang, W., Li, Y., Liu, N., Gao, Y., and Li, L. (2017). MiR-23b controls ALDH1A1 expression in cervical cancer stem cells. BMC Cancer 17:292. doi: 10.1186/ s12885-017-3192-X

Wang, Y., and Shang, Y. (2013). Epigenetic control of epithelial-to-mesenchymal transition and cancer metastasis. Exp. Cell Res. 319, 160-169. doi: 10.1016/j. yexcr.2012.07.019

Wang, Y.-D., Cai, N., Wu, X.-L., Cao, H.-Z., Xie, L.-L., and Zheng, P.-S. (2013). OCT4 promotes tumorigenesis and inhibits apoptosis of cervical cancer cells by miR-125b/BAK1 pathway. Cell Death Dis. 4:e760. doi: 10.1038/cddis.2013.272

Weber, B., Stresemann, C., Brueckner, B., and Lyko, F. (2007). Methylation of human MicroRNA genes in normal and neoplastic cells. Cell Cycle 6, 10011005. doi: 10.4161/cc.6.9.4209

Wei, J., Wu, A., Kong, L.-Y., Wang, Y., Fuller, G., Fokt, I., et al. (2011). Hypoxia potentiates glioma-mediated immunosuppression. PLoS One 6:e16195. doi: 10. 1371/journal.pone.0016195

Weller, M., Stupp, R., Reifenberger, G., Brandes, A. A., van den Bent, M. J., Wick, W., et al. (2010). MGMT promoter methylation in malignant gliomas: ready for personalized medicine? Nat. Rev. Neurol. 6, 39-51. doi: 10.1038/ nrneurol.2009.197

Wellner, U., Schubert, J., Burk, U. C., Schmalhofer, O., Zhu, F., Sonntag, A., et al. (2009). The EMT-activator ZEB1 promotes tumorigenicity by repressing stemness-inhibiting microRNAs. Nat. Cell Biol. 11, 1487-1495. doi: 10.1038/ ncb1998

Wu, L., Fan, J., and Belasco, J. G. (2006). MicroRNAs direct rapid deadenylation of mRNA. Proc. Natl. Acad. Sci. U.S.A. 103, 4034-4039. doi: 10.1073/pnas. 0510928103

Würth, R., Bajetto, A., Harrison, J. K., Barbieri, F., and Florio, T. (2014). CXCL12 modulation of CXCR4 and CXCR7 activity in human glioblastoma stem-like cells and regulation of the tumor microenvironment. Front. Cell. Neurosci. 8:144. doi: $10.3389 /$ fncel.2014.00144

Xia, Y., Choi, H.-K., and Lee, K. (2012). Recent advances in hypoxia-inducible factor (HIF)-1 inhibitors. Eur. J. Med. Chem. 49, 24-40. doi: 10.1016/j.ejmech. 2012.01.033

Xie, J., Xiao, Y., Zhu, X., Ning, Z., Xu, H., and Wu, H. (2016). Hypoxia regulates stemness of breast cancer MDA-MB-231 cells. Med. Oncol. 33:42. doi: 10.1007/ s12032-016-0755-7

Xiong, H., Nie, X., Zou, Y., Gong, C., Li, Y., Wu, H., et al. (2017). Twist1 enhances hypoxia induced radioresistance in cervical cancer cells by promoting nuclear EGFR localization. J. Cancer 8, 345-353. doi: 10.7150/jca.16607

Yamakuchi, M., Lotterman, C. D., Bao, C., Hruban, R. H., Karim, B., Mendell, J. T., et al. (2010). P53-induced microRNA-107 inhibits HIF-1 and tumor angiogenesis. Proc. Natl. Acad. Sci. U.S.A. 107, 6334-6339. doi: 10.1073/pnas. 0911082107

Yan, H., Parsons, D. W., Jin, G., McLendon, R., Rasheed, B. A., Yuan, W., et al. (2009). IDH1 and IDH2 mutations in gliomas. N. Engl. J. Med. 360, 765-773. doi: 10.1056/NEJMoa0808710

Yang, H. W., Xing, H., and Johnson, M. D. (2015). A major role for microRNAs in glioblastoma cancer stem-like cells. Arch. Pharm. Res. 38, 423-434. doi: 10.1007/s12272-015-0574-y

Yang, J.-S., and Lai, E. C. (2011). Alternative miRNA biogenesis pathways and the interpretation of core miRNA pathway mutants. Mol. Cell 43, 892-903. doi: 10.1016/j.molcel.2011.07.024

Yang, Y., Wang, Y., Yin, C., and Li, X. (2014). Clinical significance of the stem cell gene Oct-4 in cervical cancer. Tumor Biol. 35, 5339-5345. doi: 10.1007/s13277014-1696-4

Yao, Y., Xue, Y., Ma, J., Shang, C., Wang, P., Liu, L., et al. (2014). MiR-330mediated regulation of SH3GL2 expression enhances malignant behaviors of glioblastoma stem cells by activating ERK and PI3K/AKT signaling pathways. PLoS One 9:e95060. doi: 10.1371/journal.pone.0095060

Yao-Borengasser, A., Monzavi-karbassi, B., Hedges, R. A., Rogers, L. J., Kadlubar, S. A., and Kieber-Emmons, T. (2015). Adipocyte hypoxia promotes epithelialmesenchymal transition-related gene expression and estrogen receptornegative phenotype in breast cancer cells. Oncol. Rep. 33, 2689-2694. doi: 10. 3892/or.2015.3880

Ye, F., Zhou, C., Cheng, Q., Shen, J., and Chen, H. (2008). Stem-cellabundant proteins Nanog, Nucleostemin and Musashil are highly expressed in malignant cervical epithelial cells. BMC Cancer 8:108. doi: 10.1186/1471-24078-108

Yi, R. (2003). Exportin-5 mediates the nuclear export of pre-microRNAs and short hairpin RNAs. Genes Dev. 17, 3011-3016. doi: 10.1101/gad. 1158803

Yi, R., Poy, M. N., Stoffel, M., and Fuchs, E. (2008). A skin microRNA promotes differentiation by repressing "stemness". Nature 452, 225-229. doi: 10.1038/ nature 06642

Yi, R., Qin, Y., Macara, I. G., and Cullen, B. R. (2003). Exportin-5 mediates the nuclear export of pre-microRNAs and short hairpin RNAs. Genes Dev. 17, 3011-3016. doi: 10.1101/gad.1158803

Yoshimoto, M., Cunha, I. W., Coudry, R. A., Fonseca, F. P., Torres, C. H., Soares, F. A., et al. (2007). FISH analysis of 107 prostate cancers shows that PTEN genomic deletion is associated with poor clinical outcome. Br. J. Cancer 97, 678-685. doi: 10.1038/sj.bjc.6603924

You, J. S., and Jones, P. A. (2012). Cancer genetics and epigenetics: two sides of the same coin? Cancer Cell 22, 9-20. doi: 10.1016/j.ccr.2012.06.008

Yu, F., Jiao, Y., Zhu, Y., Wang, Y., Zhu, J., Cui, X., et al. (2012). MicroRNA 34c gene down-regulation via DNA methylation promotes self-renewal and epithelialmesenchymal transition in breast tumor-initiating cells. J. Biol. Chem. 287, 465-473. doi: 10.1074/jbc.M111.280768

Yue, X., Wang, P., Xu, J., Zhu, Y., Sun, G., Pang, Q., et al. (2012). MicroRNA205 functions as a tumor suppressor in human glioblastoma cells by targeting VEGF-A. Oncol. Rep. 27, 1200-1206. doi: 10.3892/or.2011.1588

Zhang, B., Pan, X., Cobb, G. P., and Anderson, T. A. (2007). microRNAs as oncogenes and tumor suppressors. Dev. Biol. 302, 1-12. doi: 10.1016/j.ydbio. 2006.08.028

Zhang, J., Han, L., Ge, Y., Zhou, X., Zhang, A., Zhang, C., et al. (2010). miR$221 / 222$ promote malignant progression of glioma through activation of the Akt pathway. Int. J. Oncol. 36, 913-920.

Zhang, J., Yang, J., Zhang, X., Xu, J., Sun, Y., and Zhang, P. (2018). MicroRNA-10b expression in breast cancer and its clinical association. PLoS One 13:e0192509. doi: 10.1371/journal.pone.0192509

Zhang, K.-L., Han, L., Chen, L.-Y., Shi, Z.-D., Yang, M., Ren, Y., et al. (2014). Blockage of a miR-21/EGFR regulatory feedback loop augments anti-EGFR therapy in glioblastomas. Cancer Lett. 342, 139-149. doi: 10.1016/j.canlet.2013. 08.043

Zhang, L., Huang, J., Yang, N., Greshock, J., Megraw, M. S., Giannakakis, A., et al. (2006). microRNAs exhibit high frequency genomic alterations in human cancer. Proc. Natl. Acad. Sci. U.S.A. 103, 9136-9141. doi: 10.1073/pnas. 0508889103

Zhao, B., Bian, E.-B., Li, J., and Li, J. (2014). New advances of microRNAs in glioma stem cells, with special emphasis on aberrant methylation of microRNAs. J. Cell. Physiol. 229, 1141-1147. doi: 10.1002/jcp.24540

Zhao, S., Deng, Y., Liu, Y., Chen, X., Yang, G., Mu, Y., et al. (2013a). MicroRNA-153 is tumor suppressive in glioblastoma stem cells. Mol. Biol. Rep. 40, 2789-2798. doi: 10.1007/s11033-012-2278-4

Zhao, S., Liu, H., Liu, Y., Wu, J., Wang, C., Hou, X., et al. (2013b). miR-143 inhibits glycolysis and depletes stemness of glioblastoma stem-like cells. Cancer Lett. 333, 253-260. doi: 10.1016/j.canlet.2013. 01.039

Zhi, F., Chen, X., Wang, S., Xia, X., Shi, Y., Guan, W., et al. (2010). The use of hsa-miR-21, hsa-miR-181b and hsa-miR-106a as prognostic indicators of astrocytoma. Eur. J. Cancer 46, 1640-1649. doi: 10.1016/j.ejca.2010. 02.003

Zhou, L., Zhao, L.-C., Jiang, N., Wang, X.-L., Zhou, X.-N., Luo, X.-L., et al. (2017). MicroRNA miR-590-5p inhibits breast cancer cell stemness and metastasis by targeting SOX2. Eur. Rev. Med. Pharmacol. Sci. 21, 87-94. 
Zhou, X., Yue, Y., Wang, R., Gong, B., and Duan, Z. (2017). MicroRNA-145 inhibits tumorigenesis and invasion of cervical cancer stem cells. Int. J. Oncol. 50, 853-862. doi: 10.3892/ijo.2017. 3857

Zhou, V. W., Goren, A., and Bernstein, B. E. (2011). Charting histone modifications and the functional organization of mammalian genomes. Nat. Rev. Genet. 12, 7-18. doi: $10.1038 / \mathrm{nrg} 2905$

Zhu, X., Rao, X., Yao, W., and Zou, X. (2018). Downregulation of MiR-196b-5p impedes cell proliferation and metastasis in breast cancer through regulating COL1A1. Am. J. Transl. Res. 10, 3122-3132.
Conflict of Interest Statement: The authors declare that the research was conducted in the absence of any commercial or financial relationships that could be construed as a potential conflict of interest.

Copyright (c) 2019 Macharia, Wanjiru, Mureithi, Pereira, Ferrer and Moura-Neto. This is an open-access article distributed under the terms of the Creative Commons Attribution License (CC BY). The use, distribution or reproduction in other forums is permitted, provided the original author(s) and the copyright owner(s) are credited and that the original publication in this journal is cited, in accordance with accepted academic practice. No use, distribution or reproduction is permitted which does not comply with these terms. 